\title{
Analytic Philosophy for Biomedical Research: The Imperative of Applying Yesterday's Timeless Messages to Today's Impasses
}

\author{
Sepehr Ehsani
}

\begin{abstract}
The mantra that "the best way to predict the future is to invent it" (attributed to the computer scientist Alan Kay) exemplifies some of the expectations from the technical and innovative sides of biomedical research at present. However, for technical advancements to make real impacts both on patient health and genuine scientific understanding, quite a number of lingering challenges facing the entire spectrum from protein biology all the way to randomized controlled trials should start to be overcome. The proposal in this chapter is that philosophy is essential in this process. By reviewing select examples from the history of science and philosophy, disciplines which were indistinguishable until the mid-nineteenth century, I argue that progress toward the many impasses in biomedicine can be achieved by emphasizing theoretical work (in the true sense of the word "theory") as a vital foundation for experimental biology. Furthermore, a philosophical biology program that could provide a framework for theoretical investigations is outlined.
\end{abstract}

The current collection of chapters in this book is organized around the theme of innovative technologies and "investing in the future." It might therefore appear as peculiar to have a chapter ostensibly focused on philosophy in such a collection.

The original version of this chapter was revised. A correction to this chapter can be found at https:// doi.org/10.1007/978-3-030-41309-5_20

\section{S. Ehsani $(\square)$}

Department of Philosophy, University College London, London, UK

Ronin Institute for Independent Scholarship, Montclair, NJ, USA

e-mail: ehsani@uclmail.net; ehsani@csail.mit.edu 
What I hope to achieve here is to make the case that despite many technological advances in biology and medicine over the past 50 years, current biomedical research paradigms are facing significant and seemingly insurmountable challenges in their theoretical foundations. This has resulted in widespread impasses in finding treatments for major categories of human diseases that might come anywhere close to being called a "cure." If we are to make real inroads, the theoretical branch of biology should be reinvigorated so that theory, in the true sense of the word, can be reintroduced to and complement experimental biology. This approach is nothing new: it worked quite well in biology in the first half of the twentieth century, and still defines the two-pronged approach that is taken in physics, i.e., theoretical and experimental physics. The history of philosophy, which until the mid-nineteenth century was indistinguishable from "science," can have many relevant lessons for how theoretical strands could be pursued in biomedicine. As such, I will first start by providing a brief overview of the current state of research outcomes in biology and medicine (disciplines which I am considering as interchangeable for the purposes here), followed by an analysis of the place of theory in biomedical research, before moving on to the discussion of the philosophical biology program.

\section{Successes and Lingering Challenges in Biomedicine Today}

As just noted, biology, particularly molecular biology, has experienced significant changes and technical innovations in the past several decades. Whereas novel insights and descriptive modes of understanding began to emerge from the early applications of molecular biology in the 1970s and 1980s, the widespread popularity of high-throughput techniques and genome sequencing in the 1990s and 2000s have led to the generation of a tremendous amount of new insights and descriptive data about the workings of the cell under normal and disease conditions (Ehsani 2013b). The human impact of these findings has been especially pronounced in the case of monogenic and/or relatively rare Mendelian diseases. A case in point here is the success of gene therapy for $\beta$-thalassemia patients (Thompson et al. 2018). Moreover, among human cancers, one can point to successful primary treatments of lymphomas and leukemias [see, e.g., Greaves (2018), Schaapveld et al. (2015)] and to overall "annual reductions of 1 to $2 \%$ in age-adjusted cancer mortality rates in the United States for many years" (Varmus 2016). Relatedly, "childhood cancer was once a death sentence, but today more than $80 \%$ of children and teenagers survive long term," with the important caveat that "adults who survive cancer as children can suffer long-term health effects" (Couzin-Frankel 2019). In the domain of infectious diseases, the recently rising cure rates in hepatitis $\mathrm{C}$ cases are especially noteworthy (Rehermann 2016).

Despite these positive examples, contrary to initial expectations, most common human diseases have remained refractory to various (non-symptomatic) therapeutic interventions, mostly because we have not been able to unify the diseases under common causative models or mechanisms. In fact, we may often observe in molecular biology research that finding a new "mechanism" in a cellular process 
comes to only mean finding "a molecule that is involved in the process" (Garfinkel 2015), which is clearly not in the true spirit of what a "mechanism" entails (Ehsani 2019). Let us consider a few examples. Mutations in the gene coding for the 3685 amino-acid Dystrophin protein implicated in Duchenne muscular dystrophy (DMD) were reported more than three decades ago (Monaco et al. 1986), but as of yet "there is no specific treatment for DMD cardiomyopathy, in large part due to a lack of understanding of the mechanisms underlying the cardiac failure" (Yucel et al. 2018). In the case of type 1 diabetes, in addition to the important issue of access to insulin, Linda DiMeglio and colleagues note that "clinicians, investigators, and patients have gained a better appreciation of the true complexity of type 1 diabetes, and humility in the face of many unsuccessful trials aimed at inducing a durable disease remission" (DiMeglio et al. 2018). In the field of Parkinson's disease research, Heiko Braak and co-authors write that "despite remarkable progress in the management of its motor symptoms by pharmacologic dopamine replacement or deep brain stimulation, there is still no cure and all attempts to develop treatments that halt or slow down the relentless progression of the disease have so far failed" (Braak et al. 2018). A similar diagnosis can be said of Alzheimer's disease (AD) research. Commenting on the halt of a trial on inhibiting the $\beta$-secretase (BACE) enzyme, Paul Aisen writes:

\footnotetext{
This is one more terribly disappointing result in our field. BACE inhibition would seem to be a powerful tool against the accumulation of toxic amyloid species that drives AD neurobiology in the early stages of the diseases. Secretase inhibition has been a leading candidate for primary prevention. But both $\gamma$-secretase and $\beta$-secretase inhibition are associated with a risk of cognitive worsening and other adverse effects that have halted all major development programs of these drugs to date. Off-target and on-target mechanisms behind these effects remain uncertain. It is possible that substantial inhibition of amyloid peptide generation interferes with synaptic function. (Aisen 2019)
}

Moving on, what about the case of infections and the immune system? Writing in 2012, the microbiologist Kim Lewis conveyed the important message that "the more we know about antibiotics, the fewer we can discover" and that "this is essentially why the field is in trouble - only one antibiotic belonging to a new class, the narrow-spectrum daptomycin, was discovered and made it into clinical practice in the past 50 years" (Lewis 2012). Advising on treatment strategies for malaria, the WHO Strategic Advisory Group on Malaria Eradication warned that "even with our most optimistic scenarios and projections, we face an unavoidable fact: using current tools, we will still have 11 million cases of malaria in Africa in 2050" (WHO 2019). In the case of cancer immunotherapy, Alex Jaeger and colleagues make the following observation: "Despite the accumulation of extensive genomic alterations, many cancers fail to be recognized as 'foreign' and escape destruction by the host immune system. Immunotherapies designed to address this problem by directly stimulating immune effector cells have led to some remarkable clinical outcomes, but unfortunately, most cancers fail to respond, prompting the need to identify additional immunomodulatory treatment options" (Jaeger et al. 2019). This is compounded by the fact that "the majority of proposed anticancer treatments do not succeed in advancing to clinical use because of problems with efficacy or toxicity, often for unclear reasons" (Lin et al. 2019). 
The overview of challenges in the pathobiological research just provided may not be surprising because many seemingly "lower-hanging-fruit" problems in biology remain open and appear to be intractable, or at least quite difficult, for us to gain a clear understanding of in the context of current research frameworks. Just to illustrate this point, let us review some examples at different levels of "complexity."1 At the basic, chemical level, deciphering the chemical structure of water, which is of paramount importance for questions such as the elucidation of protein structure, is a matter of great challenge in physical chemistry and an area of active research (Tulk et al. 2019; Yang et al. 2019). At the protein level, a big mystery is the presence of "intrinsically disordered" domains in the structure of proteins (Robustelli et al. 2018), with different functions attributed to their presence [see, e.g., Shrinivas et al. (2019)]. Also at the protein level, there is the question of the enigmatic in vivo formation of protein crystals (e.g., Charcot-Leyden crystals formed of the Galectin-10 protein $)^{2}$ implicated in inflammatory and other unknown (and "normal") biological processes (Allen and Sutherland 2019; Persson et al. 2019). At the cellular level, cell structures that might be sensitive to magnetic field changes remain controversial (Servick 2019). At the organism level, new types of puzzlement come to light. One such puzzle is stated as follows by the immunologist Simrit Parmar: "A fetus is 50\% mum and $50 \%$ dad-it's effectively the biggest allogeneic transplant in biology [...] Nature itself has created a mechanism to stop the baby being rejected by using [regulatory $\mathrm{T}$ ] cells to protect against the inflammatory onslaught from the mother's side" (Arney 2018). Understanding facets of this natural puzzle better would have implications for conditions such as graft-versus-host disease. Moving on to the pharmacological level, there are still many research questions to be asked concerning the "inactive" ingredients (excipients) in pharmacological formulations that are meant to have one "active" ingredient, and, more generally, what makes for an "active" versus "inactive" ingredient (Reker et al. 2019). Of course, cells in the body do not discriminate between active and inactive compounds, and as such excipients have individual and combined (side) effects on the body and on the active ingredient (and its putative molecular targets).

Finally, and as the last example here, at the methodological level, questions of (1) when an effect is really an effect, and (2) certainty, such as with the use of $P$-values, are salient in that they remain debatable. Matthew Kramer, as a case in point, puts forward the following suggestion: "The real question is whether a treatment effect is important, not whether it differs 'significantly' from a control. To answer this, the researcher should justify beforehand how large the effect size needs to be. Then, if a $10 \%$ improvement over the control is required, the probability that this has been attained can be calculated from the data using familiar statistical tools for hypothesis testing and sample-size determination" (Kramer 2019). John Ioannidis proposes that "focusing on effect sizes can often be better than determining whether an effect

\footnotetext{
${ }^{1}$ By "complexity" I simply mean to indicate the greater number of known (and potentially unknown) variables involved in a given level of investigation of a biological phenomenon.

${ }^{2}$ These crystals were identified in the 1850s (Su 2018).
} 
exists." Overall, perhaps Albert Einstein (1879-1955) said it best in 1922, albeit in a different context, when he observed that "as far as the laws of mathematics refer to reality, they are not certain; and as far as they are certain, they do not refer to reality" (Einstein 1922).

What I think the various challenges at different levels of investigation reviewed in this section point to is that substantial work needs to be done on the theoretical underpinnings of biological questions: theoretical work that should start with the simpler questions, ones for which fewer potential variables could be envisaged.

\section{The Current State of Theory in Biomedical Research}

A reaction to the need for theory reintroduction to biomedicine might be to state that, surely, theory does exist in the field today. It is evident that theory has always been an indistinguishable part of the modern biological sciences, from ecology (Odenbaugh 2013), evolutionary theory, and microbiological basis of disease (Shou et al. 2015) to the elucidation of DNA and protein structures and networks of gene regulation (Britten and Davidson 1969; O’Malley 2010). Lymphocytic V(D)J recombination in adaptive immunity (Dong et al. 2015) and the elucidation of friction reduction by bacteria in their medium (Hatwalne et al. 2004; Lopez et al. 2015; Marchetti 2015) are two instances of the successful implementation of a strong theoretical model through to experimental validation. Another example of the usage of sound theoretical arguments in advance of establishing an experimental paradigm is the focus on siderophore quenching strategies to avoid the emergence of antibiotic resistance in a bacterial community (Ross-Gillespie et al. 2014), which in essence shift the burden of antibiotic resistance from individual bacterial cells or colonies to a microbial community. In fact, it appears that the immune system may utilize a similar strategy as part of its own defensive mechanisms (Nakashige et al. 2015).

Nevertheless, the theoretical underpinnings that do currently exist, barring some exceptions, are not part of a systematic framework of investigation that is adhered to consciously. In fact, in the era of high-throughput and big-data experiments, a notion has become prevalent that observations and data collection can be pursued independently of prior theories. This cannot be the case, since no process of data collection, however carefully planned, can be completely devoid of bias (MacCoun and Perlmutter 2015). Again in the words of Einstein, "it is the theory that determines what we can observe," a statement which was followed by the theoretical physicist Werner Heisenberg's (1901-1976) comment that "we have to remember that what we observe is not nature in itself, but nature exposed to our method of questioning" (Bodner 1986). A pertinent example here could be the utility of Alan Turing's (1912-1954) theoretical reaction-diffusion model to the observation of "Turing-like features in the periodic pattern of digits" in developing limb buds (Raspopovic et al. 2014; Zuniga and Zeller 2014).

Presently, "theoretical biology," with some exceptions, has become mostly synonymous with computational biology and the application of mathematical 
models to various forms of data structures. ${ }^{3}$ Congruent to this conclusion, let us consider the five modalities of theoretical biology at work today as identified by Massimo Pigliucci: (1) analytical modelling (e.g., mathematical/formal models in population genetics); (2) statistical modelling (e.g., quantitative genetics); (3) computer modelling (e.g., genetic networks); (4) verbal-conceptual models (e.g., conceptual diagrams based on experimental results); and (5) philosophy of biology (Pigliucci 2013). At the moment, however, because of a host of issues such as the great number of unknowns in even "simple" biological phenomena, "theoretical" work in the tradition of the history of rational thought (which will be touched upon in the following section) is few and far between, and even in those works that do fall into this category, it is important to point out that "approximating observational phenomena is very different from formulating an explanatory account of a significant body of empirical data" (Everaert et al. 2015).

The time is therefore ripe to reintroduce genuine theoretical analysis back into biology. But where would new theories, or, better put, inspirations and approaches toward new empirical questions and theories, come from? One source could be philosophy (i.e., philosophy of science, philosophy of mathematics, philosophy of language, the history of philosophy, etc.), in the form of philosophical biology. ${ }^{4}$ Such an approach, distinct from (but still utilizing) the philosophy of biology, could endeavor to search for, propose, and develop questions and answers in the true spirit of the theoretical sciences using a vast array of tried-and-tested analytical philosophical tools that have been developed over many centuries. It has to be emphasized that the goal is not to produce only theories or theoretical narratives, because, in the words of the evolutionary biologist Richard Lewontin, "there is no end to plausible storytelling" (Lewontin 1998). Rather, the theories should be accompanied by inherently testable sets of questions and possible solutions.

\section{Lessons from the History of Philosophy and Rational Thought}

As the aim of this chapter is to suggest a framework whereby philosophical approaches can find their way back into mainstream biological research, a brief survey of the apposite history of philosophy and rational inquiry is presented in this section. Each subsection here, particularly Aristotle's biology, can be a vast and separate strand of investigation. Nonetheless, the purpose here is to look at snippets of inspiration for a philosophical biology framework. Before proceeding, however, it is important to point out why looking for lessons in philosophy applicable to

\footnotetext{
${ }^{3}$ For some examples, see Armiento et al. (2016), Asatryan and Komarova (2017), Bertsch et al. (2017), Editors (2016), Leek et al. (2010), Tadrist and Darbois-Texier (2016), Weiss et al. (2003).

${ }^{4}$ The phrase "philosophical biology," or "philosophical science" in general, would have seemed pleonastic to the scientists of the Enlightenment and later periods, but today this pleonasm may be necessary.
} 
current problems in biomedicine could be a fruitful strategy: first, philosophy does not have a "state-of-the-art." This is fortunate, I think, because philosophy is simply a mode of thought and inquiry that once arrived at, can stand the test of time and be applicable to different situations and scenarios. This is not surprising, because modern humans' cognitive capacities have not changed much since the emergence of our language faculty (Berwick and Chomsky 2015, 2017), and as such the philosophical achievements of Plato (ca. 428-348 BC) or Aristotle (384-322 BC) more than 2400 years ago may represent some of the limits of what could be achieved theoretically in certain domains of thought. Second, true philosophy is not based on mere debates, ${ }^{5}$ where there is no room for the interlocutors to change their minds and learn from the other, but rather, philosophy is based on arguments that could build on each other and that allow for thought experiments to advance one's knowledge.

\subsection{Ancient Philosophy}

Plato's dialogues offer a wealth of concepts relevant to the discussion here. The rational question-and-answer-based method Plato uses in the dialogues is usually called the Socratic (or "elenctic") ${ }^{6}$ method, which is of a "maieutic"7 nature (Leigh 2007). In other words, a sequential and adaptive question-based style of reasoning can lead one (or a group of individuals) to introspect toward new and improved reasoning. This can be said to parallel the process of hypothesis generation in a scientific inquiry. Each dialogue, such as the Theaetetus, provides specific instances of the usages of this methodology. Clark Glymour and colleagues point out that the dialogue Meno is "the source of a [philosophical] method: conjecture an analysis, seek intuitive counterexamples, reformulate the conjecture to cover the intuitive examples of the concept and to exclude the intuitive non-examples; repeat if necessary" (Glymour et al. 2010). This seems to be the perfect recipe for thought experiments.

One can also find hints of the use of simple models for testing or observation before moving on to the actual phenomenon in question. This can be read in the Sophist, when the Eleatic Stranger/Visitor says to Theaetetus, a mathematics pupil (and later of great fame as a geometer): "when it comes to grappling effectively with any of the big subjects, everyone has long thought it best to practise on small and easier things before moving on to the big ones themselves" 8 (218c5/d1) and also that "we should pursue something of no consequence and try to establish it as a

\footnotetext{
${ }^{5}$ Any point, however absurd or incorrect, could theoretically be debatable or arguable, and if this becomes the basis of a philosophical and scientific investigation, there would be no room for true progress.

${ }^{6}$ From the Greek elegkhos "refutation."

${ }^{7}$ From the Greek maieutikos "acting as midwife."

${ }^{8}$ The Sophist translations are from Christopher Rowe's edition (Plato 2015).
} 
model for the more important subject" (218d5). There is an analogous message in Aristotle's Parts of Animals (PA): "If any person thinks the examination of the rest of the animal kingdom an unworthy task, he must hold in like disesteem the study of man. For no one can look at the primordia of the human frame-blood, flesh, bones, vessels, and the like-without much repugnance" (PA I.5) ${ }^{9}$

In addition to philosophy and logic, Aristotle's perceptive and meticulous observations of nature make him a foremost naturalist (Romanes 1891). His writings on biology have received varying levels of attention from scholars in different periods. Sophia Connell notes that "because Aristotle himself does not attempt to distinguish the biological from the philosophical, it makes sense to read all Aristotelian texts as potentially representative of the same philosophical outlook" (Connell 2001). A great portion of Aristotle's observations are detailed descriptively which may be followed by inferred conclusions. The observations themselves may be firsthand or referenced from others. Commenting on Aristotle's History of Animals (HA), for example, I. M. Lonie notes: "In a celebrated passage [HA III.2 and III.3] [Aristotle] describes the theories of Syennesis, Diogenes of Apollonia, and Polybus, on the blood vessels, in all of which the heart is subordinate to the brain. After recording their views, Aristotle remarks [HA III.3] that these men and other natural philosophers were mistaken: the blood vessels begin from the heart, not from the brain" (Lonie 1964).

But there are also general accounts to be found in Aristotle's biology. A case in point is his four categories of traits which could frame one's investigation of life in nature: ways of life (bioi), actions and activities (praxeis), dispositions and character (ethê), and parts (moria) (Depew 1995). Of these general accounts, I would like to point to a few methodological proposals. First, in PA I.4, Aristotle indicates analogy and difference measurements as two modes of comparison: "Groups that only differ in degree, and in the more or less of an identical element that they possess, are aggregated under a single class; groups whose attributes are not identical but analogous are separated." The method of "the more and the less" is quite reminiscent of the earlier discussion on $P$-values and effect size. ${ }^{10}$

In the Generation of Animals $(G A)$, Aristotle makes an important distinction between the potential and the actual, stating that "all three kinds of soul [nutritive, sensitive and rational] ... must be possessed potentially before they are possessed in actuality" (GA II.3). ${ }^{11}$ In De Anima (On the Soul) III.5, he explains this notion to a greater extent, writing that "in a sense light makes potential colours into actual colours." 12 Connell provides a further helpful example from Metaphysics IX.7: "is

\footnotetext{
${ }^{9}$ From William Ogle's translation (Aristotle 1882) (see also: online text by D. C. Stevenson, The Internet Classics Archive, MIT; classics.mit.edu/Aristotle/parts_animals.html).

${ }^{10}$ There are commonalities here with John Stuart Mill's "method of difference" (Mill 1843).

${ }^{11}$ From Arthur Platt's translation (Aristotle 1910) (see also: online text at Wikisource digital library; en.wikisource.org/wiki/On_the_Generation_of_Animals).

${ }^{12}$ From J. A. Smith's translation (Aristotle 1931) (see also: online text by D. C. Stevenson, The Internet Classics Archive, MIT; classics.mit.edu/Aristotle/soul.3.iii.html).
} 
earth potentially a human being? No [ ... just as earth is not yet potentially a statue, because it must undergo a change before it becomes bronze" (Connell 2001). The potential/actual dichotomy may first and foremost bring to mind today's fields of developmental biology and genetics/inheritance. But it also brings into discussion the potential role of a living being's environment, and epigenetics. Although beyond the purview of our present discussion, I think it is important to mention that reading the $G A$ with an eye on epigenetic development (Henry 2018) should always be accompanied by the determinants of "scope and limit": A fish embryo, although susceptible to certain variations, cannot naturally develop into a bird, or another species: a scope comes hand-in-hand with limits, and therefore epigenetic variation in development is considerably constrained. ${ }^{13}$

A third, and perhaps the most famous of Aristotle's methodological proposals, is the categorization of causes. In Physics II.3, he introduces the four as follows ${ }^{14}$ : Material cause is "that out of which a thing comes to be and which persists," e.g., "the bronze of the statue." Formal cause is "the form or the archetype." Efficient or moving cause is "the primary source of the change or coming to rest" or "what makes of what is made and what causes change of what is changed." Final cause is "in the sense of end or 'that for the sake of which' a thing is done, e.g. health is the cause of walking about." In giving illustrations of each of the causes, one could rely on examples from the crafts, but as Connell points out, "the natural world is not constructed and does not work just like the crafts; indeed, the reverse seems to be the case - crafts copy nature. Natural objects take priority in Aristotle's ontology, possessing properties that crafts will never be able to exemplify" (Connell 2001). Can one or more types of causes be reduced to each other under some circumstances? This appears plausible, particularly for biological applications. John Cardwell relayed a similar message more than a century ago: "as 'form' includes, by definition, all the properties of a material thing, the 'formal cause' may, in some instances, include both the 'efficient' and 'final' causes, thus reducing the four to two, and bringing one back to the primal dual postulate, i.e., matter with "form", (Cardwell 1905).

This dual theme of matter and form is quite important and pertinent to some of the current impediments in biomedical research, for the focus in the disciplinefor practical or other reasons-has usually solely been on material causation. Here in particular I have in mind the mechanistic framework of investigation in contemporary cellular and molecular biology. Might it be possible to augment

\footnotetext{
${ }^{13}$ Noam Chomsky made a very pertinent comment related to this point in 1983: "Consider something that everybody agrees is due to heredity - the fact that humans develop arms rather than wings. Why do we believe this? Well, since nothing in the fetal environments of the human or bird embryo can account for the differences between birds and men, we assume that heredity must be responsible. In fact, if someone came along and said that a bird embryo is somehow 'trained' to grow wings, people would just laugh, even though embryologists [context: 1983] lack anything like a detailed understanding of how genes regulate embryological development" (Chomsky 1983). ${ }^{14}$ From R. P. Hardie and R. K. Gaye's translation (Aristotle 1930) (see also: online text by D. C. Stevenson, The Internet Classics Archive, MIT; classics.mit.edu/Aristotle/physics.html).
} 
mechanisms with biological "binding principles," with the former acting as the material and the latter as the formal causes in an intelligible account of a biological phenomenon (Ehsani 2019)? Moreover, a research area today where ascriptions of causality are in need of significant attention and work might be the field of randomized controlled trials, which "seem poorly suited for answering questions related to why therapies work in some situations and not in others and how therapies work in general" (Carey and Stiles 2016). In these trials, it is not uncommon to have a classification called "all-cause mortality." In a trial published in 2018 (McNeil et al. 2018), for example, the list of all-cause mortality included: cancer, cardiovascular disease, major hemorrhage, "other," and "insufficient information" (12 out of 1052 patients). For concepts such as "all-cause mortality" and related (and derived) theoretical notions, much can be done along the theme of this section.

Aristotle's methodology may often be thought to revolve around aporía (i.e., difficulties, impossibilities or puzzles). Michael Frede makes a connection between Aristotle's approach to such puzzles and that of Plato in the Sophist: "[The Sophist] sets out carefully constructing a series of puzzles, aporiai [ . . and] then it turns toward a resolution of these aporiai. In this regard the procedure of the dialogue reminds one of the methodological principle Aristotle sometimes refers to and follows, the principle that on a given subject matter we first of all have to see clearly the aporiai involved before we can proceed to an adequate account of the matter, which proves its adequacy in part by its ability both to account for and to resolve the aporiai" (Frede 1992, p. 423).

A few centuries after Aristotle, Galen (of Pergamon, (ca. 129-210 AD)) also made his own lasting impressions on the philosophical pursuit of human biology. ${ }^{15}$ Ronald Christie reminds us that "what Galen taught is of great importance since his writings dominated medical education for the next 1500 years" (Christie 1987). Eva Del Soldato, writing on the "Renaissance debate over the superiority of Aristotle or Galen," observes that "Aristotle was regarded by physicians as an important authority because of his philosophical system, but Galen had offered in his works more precise observations of the human body. Nonetheless, since many points of their disagreement (e.g., the localization of the brain functions) were merely founded on speculation, some doctors preferred to demonstrate the harmony between Aristotle and Galen in order to overcome this impasse" (Del Soldato 2019). Galen himself thought highly of Aristotle and Hippocrates ${ }^{16}$ : "All these and many other points besides in regard to the aforesaid faculties, the origin of diseases, and the discovery of remedies, were correctly stated first by Hippocrates of all writers whom we know, and were in the second place correctly expounded

\footnotetext{
${ }^{15}$ Interestingly, and of relevance here, one of Galen's writings is entitled "The Best Doctor is Also a Philosopher" (Quod optimus medicus sit quoque philosophus) (Singer 2016).

${ }^{16}$ One would expect, perhaps, that given Aristotle's focus on health and disease, he would have discussed the work of Hippocrates the physician (ca. 460-370 BC) (distinguished from the geometer/astronomer Hippocrates of Chios) in some fashion, but I have only found one reference in the Aristotelian corpus to Hippocrates in Politics VII.4.
} 
by Aristotle" (On the Natural Faculties II.4). ${ }^{17}$ It is in this context that I would like to briefly move back a few centuries before Galen and mention Erasistratus (ca. 304-250 BC), who "was regarded by his followers as a successor to Aristotle and Theophrastus" (Lonie 1964). Christie, writing on Galen's critical reception of the teachings of Erasistratus, remarked that "the school of the Erasistrians survived until after the time of Galen, who did a great disservice to medical progress by destroying its credibility with rhetoric based on sarcasm and ridicule" (Christie 1987). This is due to the fact that "Erasistratus discarded most of the humoural theory of disease in favor of one based on changes in individual organs," which is closer to modern medical approaches. But in certain other areas, Erasistratus did not make progress from today's point of view: Lonie, for example, points out that "what prevented Erasistratus, and any other ancient physiologist, from advancing a systematic hypothesis on the circulation of the blood was not so much the failure to realize how it might be possible mechanically. The obstacle was more deepseated than that: it was a failure to see beyond the analogies which they employed in their physiological systems [e.g., the blood supply vs. an irrigation system]" (Lonie 1964). Here one is again reminded of the machine analogy that is inherently tied to mechanistic accounts in modern biology. Other commonly-used analogies such as protein "folding," "intrinsic disorder," and "interaction" are further instances of this phenomenon. Overall, being cognizant of the limitations of analogies borrowed from their ordinary language usage may limit their potential pitfalls.

\subsection{After the Galilean Revolution in Science}

If openness toward natural puzzles, paradoxes, and thought experiments is one message from the preceding section, then perhaps Galileo Galilei (1564-1642) is a quintessential figure in the history of rational thought adhering to this method. Galileo allowed himself to be puzzled by seemingly mundane phenomena, leading him to perform "scientific" (i.e., rational) thought experiments where few othersas far as can be ascertained-had made any significant advances. Nowhere is this more pronounced than his thought experiment about a moving ship (1632), which convincingly demonstrated that to a person present on a stationary ship versus one on a moving ship with constant velocity, all types of motion would appear the same in both scenarios. The result of Galileo's work, along with those of René Descartes (1596-1650) and Cartesian philosophers following him was the establishment of the mechanical philosophy as an intelligible overarching account of natural phenomena and the appreciation that the world was directly understandable (Chomsky 2009). The new science of mechanics of Isaac Newton (1643-1727) changed all of this, whereby action at a distance could no longer allow for a cogent account of "matter" and "physical" to be given. Thus, the effect of the new Newtonian mechanics was to

\footnotetext{
${ }^{17}$ From Arthur John Brock's translation (Galen 1916) (see also: online text by D. C. Stevenson, The Internet Classics Archive, MIT; classics.mit.edu/Galen/natfac.html).
} 
revive some of the Aristotelian (and Scholastic) notion of "mysteriousness" in the science of the day. Indeed, this mysteriousness about the nature of matter remains to this day.

What Newton tried to avoid was "explaining what is 'unknown' by what is 'more unknown"” (Cohen and Smith 2004, p. 25). This mantra, along with Christie's caution against "dogmatism [which] can be a dishonest or insincere substitute for ignorance" (Christie 1987), become especially apropos if the implications of Newton's undermining of the mechanical philosophy are to be implemented. Namely, post-Newton, it became clear that the world cannot be directly intelligible and hence only the intelligibility of theories about the world could be contemplated (Chomsky 2014b). When one attempts to-in the words of the physician Paracelsus (1493-1541)_ “inquire of the world" (Lister 1957), rather than merely recording and measuring it, the end result of the process would be to attain simpler, more intelligible and better explanatory theories. Therefore, theory is not removed from the reality of nature; rather, as far as we as human beings can tell, theory is our reality of nature.

Let us now pick one important theory of nature, i.e., that of causality, and briefly investigate how it changed post-Galileo compared to Aristotle's account of the four causes. John Locke (1632-1704), in the first volume of his 1689 An Essay Concerning Human Understanding, offered an account of causality that may still inform today's use of mechanistic explanations in biology: "for to have the idea of cause and effect, it suffices to consider any simple idea or substance, as beginning to exist, by the operation of some other, without knowing the manner of that operation" (Locke 1894). ${ }^{18}$ A few decades later (in 1748), David Hume (1711-1776) offered an account of causality, and a commentary on its "ultimate springs and principles," that rings true with an enduring tone:

Hence we may discover the reason why no philosopher, who is rational and modest, has ever pretended to assign the ultimate cause of any natural operation, or to show distinctly the action of that power, which produces any single effect in the universe. It is confessed, that the utmost effort of human reason is to reduce the principles, productive of natural phenomena, to a greater simplicity, and to resolve the many particular effects into a few general causes, by means of reasonings from analogy, experience, and observation. But as to the causes of these general causes, we should in vain attempt their discovery; nor shall we ever be able to satisfy ourselves, by any particular explication of them. These ultimate springs and principles are totally shut up from human curiosity and enquiry. Elasticity, gravity, cohesion of parts, communication of motion by impulse; these are probably the ultimate causes and principles which we shall ever discover in nature; and we may esteem ourselves sufficiently happy, if, by accurate enquiry and reasoning, we can trace up the particular phenomena to, or near to, these general principles. The most perfect philosophy of the natural kind only staves off our ignorance a little longer: as perhaps the most perfect philosophy of the moral or metaphysical kind serves only to discover larger portions of it.

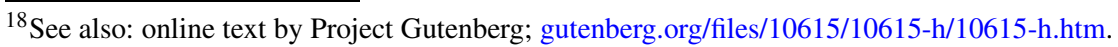


Thus the observation of human blindness and weakness is the result of all philosophy, and meets us at every turn, in spite of our endeavours to elude or avoid it. (Hume 1902) ${ }^{19}$

\section{$4 \quad$ Precedents of "Philosophical Biology"}

Looking back over the past two centuries, how can we characterize the philosophical development of the as-yet non-specialized field of "biology" among the natural sciences? Cécilia Bognon-Küss and Charles Wolfe note in their volume Philosophy of Biology Before Biology that "the word 'biology' was simultaneously and independently coined by several authors from different national and disciplinary backgrounds ([Michael Christoph] Hanov 1766, [Marie François Xavier] Bichat 1800, [Jean-Baptiste] Lamarck 1809, [Gottfried Reinhold] Treviranus 1802-1822)" (Bognon-Küss and Wolfe 2019, p. 5). Although biology was thus beginning to diverge from the more "practical" field of medicine and was perhaps more philosophical due to its theoretical origination, philosophy's role in the discipline varied contextually. For example, the eighteenth-century Scottish surgeon John Hunter (1728-1793) is said to have suggested to his vaccine-pioneering student Edward Jenner (1749-1823): "Don't think. Try" (Barry 2005; Bartley 1999). In the 1850s, Rudolf Virchow (1821-1902), the pioneer of cellular pathology (Bagot and Arya 2008), is famous for having quoted the physician Salomon Neumann (1819-1908) that "medicine is a social science" (Kottke 2011). He also stated that "medicine as a social science, as the science of human beings, has the obligation to point out problems and to attempt their theoretical solution; the politician, the practical anthropologist, must find the means for their actual solution" (JRA 2006). As a further illustration, a commentary appearing in the North American Review in 1868 stated that the "great questions of biology, considered in its philosophical aspect, are three: What is the origin of life in the first instance? What is the origin of species or the different forms of life? What are the causes of organic evolution in general?" (Abbot 1868).

It may be worthwhile to point to a number of more specific cases in this period where philosophy, theory and experimentation demonstrate an intertwined relationship. To begin with, in 1806, the chemist Theodor Grotthuss (1785-1822) proposed a theory of proton tunneling across hydrogen bonds (Cukierman 2006). The Grotthuss mechanism remains an enigmatic and very relevant question and phenomenon in studies of water structure and water-protein interactions. Theoretical investigations into hydrogen bonding in water remain an active area of research, as for example the theoretical chemist David Clary notes that "the excellent detailed agreement between the quantum dynamical calculations and experimental data shows that theory is getting much closer to a highly accurate description of water and, thus, to providing a detailed quantitative understanding of hydrogen-bond

\footnotetext{
${ }^{19}$ Based on the posthumous edition of 1777 , Section IV (see also: online text by Project Gutenberg; gutenberg.org/files/9662/9662-h/9662-h.htm).
} 
dynamics" (Clary 2016). In 1872, the physician Casimir Davaine (1812-1882) put forth the idea of "passages" in microbiology by studying Bacillus anthracis virulence in blood samples, a concept that has been a mainstay of any microbiological experiment up to this day. The duality of "humoralism" versus "cellularism" began to take shape in 1882, with the development of Ilya Metchnikoff's (1845-1916) theory of phagocytosis (Tauber 2003). Although initially derided by some as a "fairy tale" (Vikhanski 2016), this theory still resonates today in immunological research on phagocytic cells and inflammation (Gordon 2016). Around the same period, Louis Pasteur's (1822-1895) "discovery that microbes discriminate between $D$ - and $L$-substrates [...] had been given little attention until taken up by [Emil] Fischer [1852-1919], who suggested that 'the yeast cells with their asymmetrically formed agent are capable of attacking only sugars of which the geometrical form does not differ too widely from that of $D$-glucose'" (Barnett and Barnett 2011), leading to Fischer's proposition of a "lock and key" metaphor in 1894. The interaction between theory and observation was not always harmonious, in hindsight. For example, Bacillus icteroides was proposed in 1896 (by Giuseppe Sanarelli, 1864-1940) as a bacterial cause of yellow fever which fulfilled Koch's postulates. Similarly, based on the prevalent germ theory of the early twentieth century, investigators' finding of the bacterium Haemophilus influenzae in influenza patients was a perfectly reasonable and suitable answer for the cause of influenza. Only a few decades later was a virus identified as the cause through the work of Richard Shope (19011966) and colleagues (Van Epps 2006). In fact, Oswald Avery's (1877-1955) work on DNA was a result of his decades-long work on influenza and pneumonia in the same period [for an in-depth discussion, see Barry (2005)]. These examples show approaches that started with a philosophical theory followed by selective experimentation, leading eventually to a more refined theory. Nevertheless, there were instances where this model did not apply. For example, in 1909, Paul Ehrlich (1854-1915) and his collaborators tested 900 chemical compounds for a syphilis treatment to eventually identify Salvarsan, which we could venture to call one of the earliest precursors (since the heydays of alchemy) of today's high-throughput compound screens. This approach relied more on trial-and-error than ab initio theorizing.

The first half of the twentieth century saw the formalized emergence of theoretical and experimental branches in physics, a division that might not have seemed necessary beforehand, but one which continues to the present. Biology saw similar developments. In the 1930s, after the work of investigators such as J. B. S. Haldane (1892-1964), Ronald Fisher (1890-1962) and Sewall Wright (18891988) had established population genetics and the modern synthesis in evolutionary biology, C. H. Waddington (1905-1975) and Ludwig von Bertalanffy (1901-1972), among others, proceeded toward formalizing "theoretical biology" and "systems biology," respectively [see, e.g., Moya (2015)]. In 1968, the philosopher Marjorie Grene published "Approaches to a Philosophical Biology" on the state and outlook of the philosophy of biology and, over the next several decades, elements of philosophical approaches to biology were further extended into medical humanities (e.g., in Hans Jonas's 1966 publication on phenomenology and bioethics in "The 
Phenomenon of Life: Toward a Philosophical Biology"), philosophical psychology, philosophy of chemistry, philosophical chemistry (tracing its roots at least back to the work of Joseph Black, 1728-1799), physical oncology (Frieboes et al. 2011), healthcare improvement theory (Davidoff et al. 2015) and other related disciplines. Nevertheless, with the advent of recombinant DNA technology in the 1970s followed by molecular biology and the widespread adoption of relevant technologies such as flow cytometry (Robinson and Roederer 2015), theoretical/philosophical biology did not have an opportunity to reach the same level of attention as its counterpart in physics, and today, as noted earlier, many consider theoretical biology to be synonymous with computational and mathematical biology. This is not to say that questions pertaining to theoretical biology have been forgotten. Some of these questions have indeed been rigorously pursued under the domain of philosophy of science/biology, focusing on problems in evolutionary theory or population genetics, amongst others [see, e.g., Gare (2008) and Gouvêa (2015)].

Among the developments in philosophical biology in the first half of the twentieth century, there is perhaps a singular work which stands out given the scope of our analysis: Joseph Henry Woodger's (1894-1981) Biological Principles (1929), which in many respects reads farsighted from today's vantage point [see also Nicholson and Gawne (2014)]. Woodger writes in the preface that he takes inspiration from works of the philosophers C. D. Broad (1887-1971) and Alfred North Whitehead (1861-1947). He shines a spotlight, for example, on Whitehead's statement in his Science and the Modern World (1925) that "the progress of biology and psychology has probably been checked by the uncritical assumption of halftruths. If science is not to degenerate into a medley of ad hoc hypotheses, it must become philosophical and must enter into a thorough criticism of its own foundations." Although Woodger does not use the phrase "philosophical biology," he refers to "theoretical biology" more than 20 times, and writes: "Only two types of theoretical biology have so far been devised, both involving using the analogy of a humanly constructed machine: (1) vitalism (with a mechanic), and (2) the 'machine theory' (without a mechanic). This provides no independent biological way of thinking, because machines presuppose organisms" (Woodger 1929, p. 441). Again on mechanisms, and responding to Haldane, he remarked that "it is always possible to defend microscopic mechanism in principle, if any one wishes to do so, by making your mechanism complicated enough, and by 'postulating' enough sub-mechanisms to meet all contingencies. It cannot then be refuted, but neither can it be verified. All I have undertaken to do is to show the undesirability of restricting biological thought in this way" (Woodger 1929, p. 485). This is germane to our earlier focus on mechanisms. Lastly, he observed the following of the state of biology at the time: "biology [...] is still in the metaphysical stage: too eager to press on to startling 'conclusions' rather than to devote critical attention to the purification of its concepts and making more sure of its foundations. The accumulation of data, still less the erection of speculative theories, is not enough" (Woodger 1929, p. 84). 


\section{$5 \quad$ The Imperative for a Coherent and Unified Theoretical and Philosophical Biology}

Based on the historical precedents expounded thus far, and the current state of biomedical research outcomes, it appears vital to renew the application of philosophical reasoning to theoretical biology research. Philosophical biology would be biology through philosophy, with the aim of gaining insights into foundational questions in biology using a philosophical approach. Its objectives would, in essence, be similar to the ideals of the physical sciences community in the early period of theoretical physics in the 1920s and 1930s. In fact, Max Born (1882-1970) commented in 1963 that "I am now convinced that theoretical physics is actually philosophy." Nevertheless, although the goals would be similar, it is evident that biology and physics are dissimilar in many ways and not necessarily reducible to each other. As Robert Berwick and Noam Chomsky point out, "biology is more like case law, not Newtonian physics" (Berwick and Chomsky 2015, p. 36).

\subsection{Contours of a Revived Philosophical Biology}

A primary concern of philosophical biology would be the development of models in biology. Baruch Spinoza (1632-1677) pointed out a common fallacy regarding models in his magnum opus Ethics (1677): "for men are wont to form general ideas both of natural phenomena and of artifacts, and these ideas they regard as models, and they believe that Nature [...] looks to these ideas and holds them before herself as models. So when they see something occurring in Nature at variance with their preconceived ideal of the thing in question, they believe that Nature has then failed or blundered and has left that thing imperfect" (Spinoza 1992). In other words, testing a model against a natural phenomenon is different than testing the said natural phenomenon against the said model, an issue which is as relevant today as it was more than 300 years ago, and harks back to the historical discussion post-Newton about intelligible theories about the world - a world which is not directly intelligible. Jeremy Gunawardena defines a model as "some form of symbolic representation of our assumptions about reality" (Gunawardena 2014a), with "assumptions" here being a key term. Gunawardena further describes the duality between informal models (mental, verbal, etc.) and formal models (mathematical) in biology. Now, whereas assumptions about reality are tested daily in the laboratory, and formal models are developed in computational/mathematical biology, informal models, as a bridge between our assumptions about reality and symbolic representations of those assumptions, are ripe for philosophical investigation. ${ }^{20} \mathrm{~A}$ second primary concern of philosophical biology would be on studying the "limits" of our current understanding in biology. What is accessible to us today and what is not? What can we reasonably expect to find and understand

${ }^{20}$ See also Orzack (2012). 
about the cell, given that not finding something does not indicate its nonexistence? Again, drawing on the common themes with theoretical physics, the following observation from the physicist Jean Baptiste Perrin (1870-1942) in his 1926 Nobel Lecture is pertinent:

Certain scholars considered that since the appearances on our scale were finally the only important ones for us, there was no point in seeking what might exist in an inaccessible domain. I find it very difficult to understand this point of view since what is inaccessible today may become accessible tomorrow (as has happened by the invention of the microscope), and also because coherent assumptions on what is still invisible may increase our understanding of the visible. (Perrin 1926)

On the whole, philosophical biology would entail an analysis that endeavors to be historically, biologically, and philosophically informed. It would also rely upon all three types of knowledge among which Spinoza drew a distinction: (1) "knowledge of the first kind" being opinion or imagination, (2) "knowledge of the second kind" being reason, and (3) intuition forming "knowledge of the third kind" (Spinoza 1992). Whether or not such an approach leads to a new or modified theory of some facet of biology, it would in any case result in greater understanding of biological phenomena. The distinction here is crucial. Understanding is a process toward the intelligibility of a concept or theory; but why or how that concept becomes intelligible to us, be it through internal analogies, comparisons with similar past experiences, etc., might be beyond the reach of our introspection. To put it differently, nature is full of surprises; to increase understanding of some natural phenomenon is to experience fewer surprises, while certainly always allowing for new puzzlements to arise. Along the same line, the philosopher and psychologist Wilhelm Dilthey (1833-1911) noted in 1894 that "we explain nature, [whereas] we understand psychic life" (Dilthey 1977), drawing a distinction between explanation and understanding.

It might be useful to suggest a few specific examples of questions and topics that a philosophical biologist could consider. These examples are divided into two categories: Theoretical Methods and Tools (TMT) and Theoretical Problems and Solutions (TPS) (Fig. 1).

\subsection{Theoretical Methods and Tools (TMT)}

When the phrase "philosophical methods" is mentioned, the logical operations of deduction and induction are usually one of the first to be invoked. To illustrate their utility using the case of the cellular basis of time as an example (Ehsani 2012b), we could say the following: (A) If (1) all biological reactions in cellular environments are synchronous and (2) all synchronous phenomena need an internal or external pacemaker, then we can syllogistically deduce that (3) all biological reactions in cellular environments are definitely driven by a pacemaker. (B) If (1) cell line $X$ has a pacemaker and (2) cell line $Y$ also has a pacemaker, then we can induce that (3) other cells may also have a pacemaker. These two methods are very useful and are in fact indispensable components of human rational reasoning in general. 


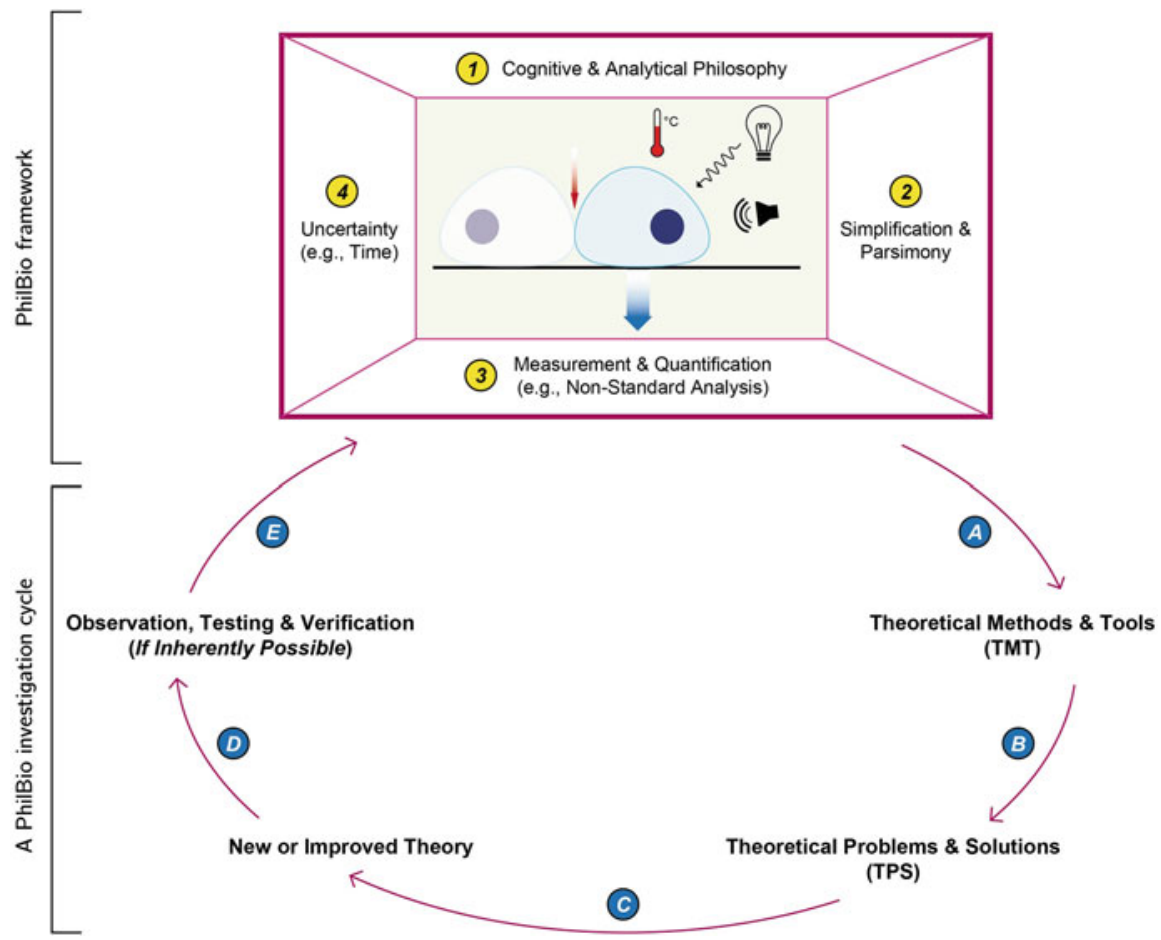

Fig. 1 A proposed outline for philosophical biology investigations. Philosophical biology ("PhilBio") can be framed as a set of perspectives to approach what is known and unknown about a given topic in biology. These perspectives could be cognizant of (1) analytical, cognitive, and rational philosophical reasoning; (2) a general goal toward simplification and parsimony; (3) novel mathematical, logical or other means of measurement; and (4) a general appreciation of uncertainty around the interface between our cognitive capacity and different hard facets of nature. An investigation that takes philosophical biology into account can (A) use these perspectives and choose one or more philosophical tools to (B) approach the problem at hand, using those tools to refine, redefine, or even dismiss the initial question. If the question is not dismissed, (C) a set of possible solutions could be proposed. The set of possible solutions could eventually be amalgamated into a new explanatory theory or account, which (D) may or may not be verifiable based on the current experimental paradigms of the period. (E) This process is repeated as more is understood about the said topic (Source: author)

Nevertheless, in proposing a set of methods and tools for philosophical biology, we could develop approaches that are more tailored to the kinds of questions that are investigated [see, e.g., Nesse (2013)]. The TMT category could include approaches that are analytical, following the works of philosophers such as Charles Sanders Peirce (1839-1914), Gottlob Frege (1848-1925) and Alfred Tarski (19011983), or could follow nonanalytical and nontraditional reasoning methods. If a philosophical biology investigation foresees a direct or an immediate human impact, the philosophical approach should be grounded in moral philosophy as a first step. Furthermore, as much as possible, one could aim to initially avoid using 
philosophical methods that provoke competing or nontrivial definitions (e.g., mereological, teleological, epistemological, tautological, phenomenological, ontological, normative, etc.) and to appeal to as-simple-as-possible rational and evidentiary approaches. Nevertheless, certain "simplified" components of the concepts in the former category should necessarily be used. Some examples include:

1. When we attempt to understand and describe the behavior of a protein or lipid membrane in a cell, how do we begin to offer a "good" explanation? Is a molecular "descriptive" account an intelligible "explanation" nonetheless? Here contemporary analytical philosophical methods that have been developed at least beginning with the work of Rudolf Carnap (1891-1970) with regards to "explication" can have utility (Friedman 1974; Weber et al. 2013).

2. In offering a descriptive or causal explanation, how do we move beyond providing a statistical view of the phenomenon at hand (Lewontin 2006)? Given current trends in biology, and the natural sciences in general, toward the expansion of numerical models and big-data science (Bauer et al. 2015), this question becomes especially important, as no natural process can have a "statistical nature"; a natural process just has a nature, which we may choose to model statistically in the absence of a suitable explanatory theory. In fact, some historians of science rightly point out the fact that "big data" is not a new notion in the sciences, as large collections of data have been a staple of astronomy, in the form of astronomical tables, for many centuries (Mozaffari 2016; Toomer 1968).

3. Because many biological interactions happen at infinitesimal scales where exact measurements give way to approximations, can "non-standard analysis" and the theory of infinitesimals (developed by Abraham Robinson, 1918-1974; published in 1966) along with hyperreal numbers (Robert 2011) be used instead of standard calculus? Can this be combined with Gödel numbering, mereology and set theory?

4. In trying to establish causal relationships in gene/protein circuits, how can we use deontic logic (which focuses on the notion of "obligation") (McNamara 2019)? Would deontic logical approaches help with questions such as does something that looks like an effect really need a cause? What role could nonclassical logic play? Here one should note that although deontic and nonclassical logical systems are themselves divided into various subcomponents, the applicability to philosophical biology would not necessarily be in the closed formal proofs that these systems allow, but more in the processes and connections that they can hint at or disprove.

5. What biological principles could be envisaged to augment mechanistic accounts in biology and medicine (Ehsani 2019)? An example here could be Xue-Xin Wei and colleagues' report on using mathematical modeling to propose that a "principle of economy predicts the functional architecture of grid cells" (Wei et al. 2015). Moreover, how can the parameters for such principles be discovered? And, how can analogous developments in the field of biolinguistics since the 1950s (Chomsky 2007) be translated to biological investigations? 


\subsection{Theoretical Problems and Solutions (TPS)}

The TPS category comprises a group of newly formed questions and possible sets of solutions that could be proposed using philosophical approaches. Moreover, the goal may at times be to come up with new or improved explanatory theories. A "good" theory is an adaptable theory, one that would allow for incremental growth in understanding while also hinting at gaps that a new and improved theory could bridge (Brigandt 2016), and, in a sense, produce a leap in understanding. Furthermore, such a theory should be developed in "abstraction from the full complexity" of what is being studied (Chomsky 1986; Martin 1980). TPS also includes existing questions or paradigms that are expanded or revised. Some examples include:

1. What is the structural difference between two helical or beta-sheet domains of equal length in two proteins arising from different amino acid sequences? Is a "disordered" domain of a protein really "disordered," or do such domains adopt a limited set of structures that are "appropriate to, but not caused by" 21 the protein/lipid microenvironment around the protein? Can new protein folding theories become alternatives to molecular dynamics simulations (Chung et al. 2015; Robustelli et al. 2018)? Is it conceivable that in some circumstances protein folding, rather than proceeding to minimize free energy (Neupane et al. 2016), proceeds primarily to minimize search efficiency only (i.e., "computational" efficiency from the perspective of the amino acid sequence)? These questions are not only important to understanding the structure and dynamics of proteins but are also indispensable in deriving new theories to account for protein aggregation in neurodegenerative diseases or prion-like propagation of proteins. Furthermore, these questions all have unresolved theoretical underpinnings that can be resolved piece by piece using philosophy. For example, if one tries to conceptualize the number of possible atom-to-atom "interactions" (a vague and problematic notion that needs resolution itself) as a nascent polypeptide chain emerges from the ribosome, the number of possibilities can easily escape finite bounds, whereas it is evident that protein folding takes place in a finite amount of time in the cell (or even under artificial conditions). An "infinite" number of possibilities resolving in a finite amount of time is reminiscent of a "supertask" in mechanical philosophy (Manchak and Roberts 2016), a concept that has been explored since the Antiquity.

2. As noted previously, given the many ambiguities about the structure of water molecules (Thamer et al. 2015; Yang et al. 2019), how do hydrophilic residues of proteins really interact with water molecules in their vicinity? Are such interactions always electrostatic in nature, or could non-electrostatic interactions, such as hydrogen-hydrogen $(\mathrm{H}-\mathrm{H})$ bonding - distinct from electrostatic hydrogen bonding (Matta 2006)_also play an important role? It should be

${ }^{21}$ Using the Cartesian terminology referred to by Chomsky in Chomsky (2009). 
noted that water is by no means the only "simple" ubiquitous molecule for which deep ambiguities remain. The $\mathrm{C}-\mathrm{H}$ bonds of the seemingly simple methane molecule $\left(\mathrm{CH}_{4}\right)$ are another case in point (Smith et al. 2016), a strand of investigation which could have implications for $\mathrm{C}-\mathrm{H}$ bonds in amino acids. Moreover, given the essential interaction of many proteins with metal ions, organometallic compounds and other small molecules, do current theories satisfactorily account for the unique interaction of amino acids and these compounds $?^{22}$ It should be noted that these questions are essential primary questions not only to understand protein folding, but also protein interactions with other proteins and macromolecules. Before finding suitable answers to these questions, it is doubtful that an explanatory framework can ever reach the point where broader concepts, such as cross-species "inter-interactomes" of protein-protein interaction networks (Zhong et al. 2016), could be addressed.

3. What is the concept of time in the cell (cellular time as opposed to circadian time) (Ehsani 2012b)? Does a cell need a sub-second timekeeping or pacemaking mechanism to arrange the plethora of simultaneous functions taking place in the cytoplasm and other subcellular compartments? If so, what could such a mechanism be (Fig. 2)?

4. Can one deduce whether the time frame of a given cellular process increases polynomially with the increasing "complexity" of the task? This problem could borrow from extensive research in theoretical computer science under the famous $P$ (polynomial time) versus $N P$ (nondeterministic polynomial time) paradigm. Such questions can initially draw from existing research in computational biology regarding the protein folding problem (Berger and Leighton 1998) or RNA structure prediction (Smit et al. 2008), to name a few. One can eventually expand the scope of these investigations to include kinetic studies of enzymes and process timing in the framework of the Michaelis-Menten equation (Gunawardena 2014b; Xie 2013).

5. What exactly is aging on an organism level, and what accounts for the diversity of aging profiles across species (Jones et al. 2014; McCormick et al. 2015; Moger-Reischer and Lennon 2019) and different phyla (Hug et al. 2016; Levin et al. 2016)? As evidenced by work on the Prochlorococcus genus (Biller et al. 2015), this line of investigation would require an analysis of what it really means to be a species, a genus, etc. (Buchanan 2015; Nei and Nozawa 2011).

6. For the phenomenon of antimicrobial resistance, as alluded to earlier, can one devise a strategy where the emergence of resistance would theoretically be impossible? Since the introduction of sulfonamide antibacterial drugs in the 1930s, the emergence of resistant subpopulations of bacteria or fungi has become inevitable (Balaban et al. 2019; Fisher and Mobashery 2016). Nevertheless, notwithstanding the re-emerging bacteriophage research field (Rohwer and Segall 2015), strategies are beginning to be refurbished or de

\footnotetext{
${ }^{22}$ As an example, see Seeman and Cantrill (2016) for a discussion of the challenges in understanding the structure of the organometallic compound ferrocene.
} 


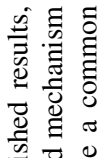

ปั)

ㅎ․ㅇㅇㅇㅇ

ธี 윯

D્ญ :

ก ำ

जी

ㅊ. 을

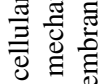

일

들 믕

잉

유

클 흘 을

E.

సٓ

(1)

\section{43}

.

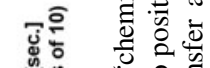

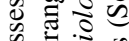

仓े $: \cong$

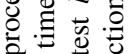

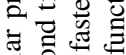

행

उ 0.5

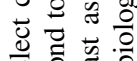

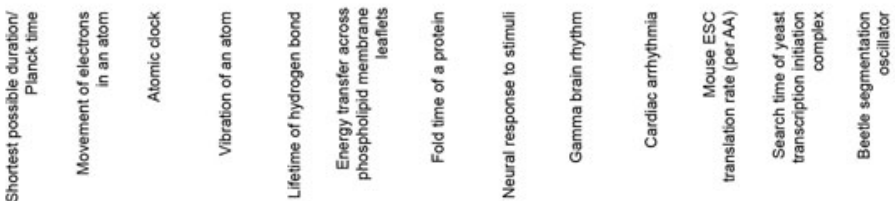

递焉

पे ठै चे

๑. 음

矛䒕

记

可志

ㄴ. 믈

운 흉 
novo devised where compound-based antimicrobial resistance would become avoidable (Baym et al. 2016; Kolter and van Wezel 2016; Lazar et al. 2013; Szybalski and Bryson 1952; Toprak et al. 2012). This is a critical and ripe area for practical philosophical contributions.

7. In cancer biology, what are the theoretical underpinnings of the occasionally paradoxical nature of metastasis (Piskounova et al. 2015), heterogeneous origins (Ling et al. 2015), differing outcomes (Nikiforov et al. 2016), and spontaneous regression (Brodeur and Bagatell 2014; Diede 2014; Hoption Cann et al. 2002; Saade Lemus et al. 2019)? How can some of these paradoxes be used as "natural experiments" (Feder and Mitchell-Olds 2003; Louis 2007; Sekikawa et al. 2003) in cancer research? Since the postulation of the Warburg effect more than 90 years ago, our understanding of cancer metabolism, and oncology in general, has greatly advanced. Nevertheless, an all-encompassing theory is still lacking. For example, in reviewing a metabolomic analysis of cancer cell proliferation (Hosios et al. 2016), Jason Tanner and Jared Rutter pose the following questions that await explanation:

Although the majority of cell protein is comprised of amino acids imported from the environment, why do cultured cells - awash in amino-acid-rich culture mediumutilize glutamine to synthesize other amino acids de novo even when those amino acids are available for import? Might this have to do with limited import capacity, or is there a separate unforeseen advantage to biosynthesis? Finally, the finding that glucose-derived carbon contributes to a small fraction of cell mass raises still more questions. Why don't proliferating cells utilize the large amounts of carbon consumed as glucose to meet their biosynthetic needs? What is the purpose of such a carbonwasting metabolic program? Is it simply that this program enables the rapid production of adequate ATP while maintaining the NAD/NADH redox balance, or is there more to it?" (Tanner and Rutter 2016)

One could speculate that these and other questions will only yield to new experimental studies if a novel explanatory theory is provided to frame and structure the plethora of pieces of knowledge already available. In fact, certain areas within the cancer research field (e.g., cancer stem cells or immunotherapy) have already benefited noticeably from philosophical and theoretical approaches (Laplane 2016; Ledford 2016; Willyard 2016; Wong and Slavcev 2015).

8. More broadly, what are the inherent differences between correlation and causation (Ehsani 2013a; Karmon and Pilpel 2016)? Do they have structural differences? For what questions might causal thinking and the notion of agency not be necessary? In areas such as neural networks, to paraphrase the pre-Socratic philosopher Heraclitus of Ephesus (ca. 535-475 BC), "is a hidden connection better/stronger than a visible connection"? Could a hidden or unobservable variable in an experiment, to borrow from economic theory, "share covariance properties with the observed variables" (Oster 2015)? ${ }^{23}$ Additionally, similar to the notion mentioned earlier for disordered domains in

${ }^{23}$ See Elf (2016), Hilfinger et al. (2016), Justman (2016) for further discussion related to this topic. 
proteins, are there biological processes that are "appropriate to but not caused by" (Chomsky 2009) the stimuli that are currently thought to be the causes of those processes? These questions are fundamental to all areas of biology, from investigating the still-unraveling workings of organelles (Delling et al. 2016; Norris and Jackson 2016) to metabolic processes (Scholl and Nickelsen 2015), cell-death pathways (Wallach et al. 2016), designing protocols that allow a smoother transition of findings from model organisms to humans (Anders et al. 2016), and human speech fluency (Lieshout et al. 2014), to name a few. It is also evident that a more thorough understanding of causative structures has direct applicability to research on disease mechanisms regardless of the degree to which the exact etiology is known [e.g., Mendelian (Chen et al. 2016; Steffan 2016) or infectious diseases (Byrd and Segre 2016)].

9. Do cellular processes that seem chaotic, stochastic or random (Capp 2012; Kadelka et al. 2013; Losick and Desplan 2008; Uphoff et al. 2016), such as bursts of transcription or Brownian-like motion of different macromolecules in the cytoplasm, in fact follow as-yet unrecognized deterministic pathways (Ehsani 2012a; Kryazhimskiy et al. 2014)?

10. What exactly is "uncertainty," and is it possible to postulate theories that go beyond a statistical description of uncertainty? For example, the American Statistical Association emphasized in 2016 that a $P$-value is "a statement about data in relation to a specified hypothetical explanation, and is not a statement about the explanation itself" (Wasserstein and Lazar 2016). In addition, are there concepts that "ought to be true" but that we cannot describe or observe with any certainty? Are there aspects of biological cells which one can never in principle be certain about? In other words, are there limits to our understanding in certain areas of biology [e.g., see Lewontin (1998)]? Some of the "low-hanging fruits" amongst these questions may initially be found in computational biology. For example, there have been efforts to identify inherent upper limits in accelerating search speeds in biological datasets (Kannan and Tse 2015). Moreover, notions of "loose and tight limits" have been defined for computational problems (Markov 2014). Furthermore, similar questions can be asked in chemistry, as for example noted by the biochemist Christopher Walsh: "how much new chemistry is yet to be found [and] what kinds of biosynthetic enzymatic transformations are yet to be characterized?" (Walsh 2015).

11. The field of neuroscience is readily conducive to philosophical and theoretical inquiries [see, e.g., Casebeer (2003), Fleming (2016), Greene (2003), Gregory (2000)]. However, in light of the numerous unsolved, lower-hanging-fruit problems in "simpler" organisms such as D. melanogaster or C. elegans, many questions regarding human cognition, the primate nervous system or the mouse brain (the circuitry of which is beginning to be mapped) may remain outside the purview of philosophical biology for some time to come. Nevertheless, there are questions that could be further refined in human cognitive science and neurobiology using philosophical biology. For example, why are "our brains [...] preprogrammed to misread certain images" (Chatterjee 2015) or what is the initiating mechanism of voluntary movements (Bizzi and Ajemian 2015)? 
12. Lastly, certain philosophy of biology threads could be investigated from a philosophical biology perspective with immediate application to both strands. The philosopher of science Paul Griffiths, for instance, writes that "when addressing [conceptual puzzles within biology], there is no clear distinction between philosophy of biology and theoretical biology" (Griffiths 2018). As a case in point, if chemistry is arguably not reducible to physics (yet unifiable at the same time) (Chomsky 2009), in the same spirit could we ask if the properties of a biological system (e.g., a cell) can ever be reduced to the properties of its component parts (e.g., proteins)? As another example, if one excludes some obvious explanations, why are certain findings either in molecular biology or clinical medicine not reproducible (Niepel et al. 2019; Open Science 2015)? Approaches to tackle these and other questions of this kind are well established in the philosophy of science literature, and therefore philosophical biology and philosophy of science are not exclusive of each other.

\subsection{Inherent and Experimental Verifiability}

Given the various lines of study suggested above in the TMT and TPS sections, what would be an endpoint to, or natural progression of, a philosophical biology investigation? Is empirical verification a necessary touchstone? Although certain outcomes of philosophical biology studies can and should be tested computationally or in a cellular biology laboratory, one can posit that experimental validation should not be the ultimate standard to validate or invalidate such strands of investigation. Again to draw an analogy with theoretical physics, early quantum physicists realized that some theoretical paradigms will, at least for the foreseeable future, remain outside the purview of experimental falsifiability in light of the inherent limits within physical experimental approaches [see, e.g., Deutsch (2015)]. The Laser Interferometer Gravitational-Wave Observatory (LIGO) experimental results act as a case in point (Abbott et al. 2016). The nonobligatory interaction between theory and experiment is not limited to physics but can also be observed in, for example, economics (Abreu et al. 2012) or biolinguistics (Hauser 2016). It is therefore to be anticipated that philosophical biology would also generate hypotheses or questions that might not be testable in the laboratory immediately, but their value would only be shown in time and in perhaps not-so-predictable manners.

Theories developed using the framework described here are certainly not endpoints in a given theoretical investigation. They are merely stepping stones toward more complete frameworks and programs, which could generate questions that are inherently empirical. A relevant example here is the culmination of many biological theories and empirical validation attempts that now form the exhaustive set of transcriptional and translational programs in developmental biology (Oates et al. 2009). This process can also be observed in biolinguistics, whereby linguistic theories that led to our current state of understanding of Universal Grammar were included in a Minimalist Program, which was then followed amongst other things by the development of the Strong Minimalist Thesis (SMT). SMT is now a robust 
explanatory framework that can allow linguists to discover the extent to which one can "account for the relevant phenomena of language" (Chomsky 2014a).

\section{Conclusions}

For the modern biological disciplines to produce genuine instances of understanding of the workings of the cell, philosophy must regain its rightful place in the theoretical foundations of biology. This is in line with the development of the natural sciences at least since the Galilean revolution in science and the Enlightenment. The overarching aim of a philosophical biology program could be to define suitably innovative and worthwhile horizons for individual parts of biomedical research, horizons that are not mere pedantic extrapolations of current technical information. Furthermore, solutions that arise from these investigations may be isomorphic, such that their theoretical structure could be applicable to other areas of the sciences, in the same line that a number of frameworks from modern linguistics have been utilized in this chapter in the context of philosophical biology.

It may be apt to end on a note that the complexities and "deep truths" of cellular processes could remain hidden even in spite of philosophical, theoretical and other sincere efforts. In the words of Attar of Nishapur (ca. 1145-1221), "the sea will be the sea, whatever the drop's philosophy." Nevertheless, one can at least be assured that a philosophical approach to biology will constantly question our questions and provide a framework for reassessing and improving our perspectives of the workings of the cell in normal and disease biology.

Acknowledgments Earlier developments of some of the ideas presented in this work have appeared in two preprint articles (Ehsani 2016, 2019). I would like to thank Philipp Plugmann for the invitation to contribute to this collection. The author's work is supported by a University College London Overseas Research Scholarship.

\section{References}

Abbot, F. E. (1868). Philosophical biology. The North American Review, 107, 377-422.

Abbott, B. P., Abbott, R., Abbott, T. D., Abernathy, M. R., Acernese, F., Ackley, K., et al. (2016). Observation of gravitational waves from a binary black hole merger. Physical Review Letters, 116(6), 061102.

Abreu, D., Pearce, D., \& Stacchetti, E. (2012). One-sided uncertainty and delay in reputational bargaining. Economic Theory Center Working Paper No. 45-2012.

Aisen, P. (2019). Comment on 'End of the BACE inhibitors? Elenbecestat trials halted amid safety concerns' (Alzforum). Retrieved September 13, 2019, from http://alzforum.org/news/researchnews/end-bace-inhibitors-elenbecestat-trials-halted-amid-safety-concerns\#comment-32966.

Allen, J. E., \& Sutherland, T. E. (2019). Crystal-clear treatment for allergic disease. Science, 364(6442), 738-739.

Anders, H. J., Jayne, D. R., \& Rovin, B. H. (2016). Hurdles to the introduction of new therapies for immune-mediated kidney diseases. Nature Reviews Nephrology, 12(4), 205-216.

Aristotle. (1882). De Partibus Animalium (On the parts of animals) (W. Ogle, Trans.). Kegan Paul, Trench \& Co. 
Aristotle. (1910). De Generatione Animalium (On the generation of animals) (A. Platt, Trans.). Clarendon Press.

Aristotle. (1930). Physica (Physics) (R. P. Hardie \& R. K. Gaye, Trans.). Clarendon Press.

Aristotle. (1931). De Anima (On the soul) (J. A. Smith, Trans.). Clarendon Press.

Armiento, A., Doumic, M., Moireau, P., \& Rezaei, H. (2016). Estimation from moments measurements for amyloid depolymerisation. Journal of Theoretical Biology, 397, 68-88.

Arney, K. (2018). Solving lymphoma's stem-cell problem. Nature, 563(7731), S48-S49.

Asatryan, A. D., \& Komarova, N. L. (2016). Evolution of genetic instability in heterogeneous tumors. Journal of Theoretical Biology, 396, 1-12.

Bagot, C. N., \& Arya, R. (2008). Virchow and his triad: A question of attribution. British Journal of Haematology, 143(2), 180-190.

Balaban, N. Q., Helaine, S., Lewis, K., Ackermann, M., Aldridge, B., Andersson, D. I., et al. (2019). Definitions and guidelines for research on antibiotic persistence. Nature Reviews Microbiology, 17(7), 441-448.

Barnett, J. A., \& Barnett, L. (2011). Yeast research: A historical overview. Washington, DC: ASM Press.

Barry, J. M. (2005). The great influenza: The story of the deadliest pandemic in history. London: Penguin.

Bartley, S. (1999). John Hunter - the scientific surgeon 'don't think, try; be patient, be accurate...'. Journal of Investigative Surgery, 12(6), 305-306.

Bauer, P., Thorpe, A., \& Brunet, G. (2015). The quiet revolution of numerical weather prediction. Nature, 525(7567), 47-55.

Baym, M., Stone, L. K., \& Kishony, R. (2016). Multidrug evolutionary strategies to reverse antibiotic resistance. Science, 351(6268), aad3292.

Berger, B., \& Leighton, T. (1998). Protein folding in the hydrophobic-hydrophilic (HP) model is NP-complete. Journal of Computational Biology, 5(1), 27-40.

Bertsch, M., Franchi, B., Marcello, N., Tesi, M. C., \& Tosin, A. (2017). Alzheimer's disease: A mathematical model for onset and progression. Mathematical Medicine and Biology, 34(2), 193-214.

Berwick, R. C., \& Chomsky, N. (2015). Why only us: Language and evolution. MIT Press.

Berwick, R. C., \& Chomsky, N. (2017). Why only us: Recent questions and answers. Journal of Neurolinguistics, 43(B), 166-177.

Biller, S. J., Berube, P. M., Lindell, D., \& Chisholm, S. W. (2015). Prochlorococcus: The structure and function of collective diversity. Nature Reviews Microbiology, 13(1), 13-27.

Bizzi, E., \& Ajemian, R. (2015). A hard scientific quest: Understanding voluntary movements. Daedalus, 144(1), 83-95.

Bodner, G. M. (1986). Constructivism: A theory of knowledge. Journal of Chemical Education, 63(10), 873-878.

Bognon-Küss, C., \& Wolfe, C. T. (2019). The idea of 'philosophy of biology before biology': A methodological provocation. In C. Bognon-Küss \& C. T. Wolfe (Eds.), Philosophy of biology before biology (pp. 4-23). Routledge.

Braak, H., Del Tredici-Braak, K., \& Gasser, T. (2018). Special issue "Parkinson's disease". Cell and Tissue Research, 373(1), 1-7.

Brigandt, I. (2016). Do we need a 'theory' of development? Biology and Philosophy, 31, 603-617.

Britten, R. J., \& Davidson, E. H. (1969). Gene regulation for higher cells: A theory. Science, 165(3891), 349-357.

Brodeur, G. M., \& Bagatell, R. (2014). Mechanisms of neuroblastoma regression. Nature Reviews Clinical Oncology, 11(12), 704-713.

Buchanan, M. (2015). Bacterial complexity. Nature Physics, 11, 887.

Byrd, A. L., \& Segre, J. A. (2016). Infectious disease. Adapting Koch's postulates. Science, 351(6270), 224-226.

Capp, J. P. (2012). Stochastic gene expression stabilization as a new therapeutic strategy for cancer. BioEssays, 34(3), 170-173. 
Cardwell, J. C. (1905). The development of animal physiology: The physiology of Aristotle. Medical Library and Historical Journal, 3(1), 50-77.

Carey, T. A., \& Stiles, W. B. (2016). Some problems with randomized controlled trials and some viable alternatives. Clinical Psychology and Psychotherapy, 23(1), 87-95.

Casebeer, W. D. (2003). Moral cognition and its neural constituents. Nature Reviews Neuroscience, $4(10), 840-846$.

Chatterjee, R. (2015). Out of the darkness. Science, 350(6259), 372-375.

Chen, R., Shi, L., Hakenberg, J., Naughton, B., Sklar, P., Zhang, J., et al. (2016). Analysis of 589,306 genomes identifies individuals resilient to severe Mendelian childhood diseases. Nature Biotechnology, 34(5), 531-538.

Chomsky, N. (1983). Things no amount of learning can teach (interview by J. Gliedman), from chomsky.info/198311__

Chomsky, N. (1986). Knowledge of language: Its nature, origin, and use. Praeger Publishers.

Chomsky, N. (2007). Biolinguistic explorations: Design, development, evolution. International Journal of Philosophical Studies, 15(1), 1-21.

Chomsky, N. (2009). The mysteries of nature: How deeply hidden. The Journal of Philosophy, 106(4), 167-200.

Chomsky, N. (2014a). Preface to the 20th anniversary edition. The Minimalist Program (20th Anniversary Edition) (pp. vii-xiii). MIT Press.

Chomsky, N. (2014b). Science, mind, and limits of understanding. The Science and Faith Foundation, Pontifical Council for Culture.

Christie, R. V. (1987). Galen on Erasistratus. Perspectives in Biology and Medicine, 30(3), 440449.

Chung, H. S., Piana-Agostinetti, S., Shaw, D. E., \& Eaton, W. A. (2015). Structural origin of slow diffusion in protein folding. Science, 349(6255), 1504-1510.

Clary, D. C. (2016). Quantum dynamics in the smallest water droplet. Science, 351(6279), $1267-$ 1268.

Cohen, I. B., \& Smith, G. E. (2004). Introduction. In I. B. Cohen \& G. E. Smith (Eds.), The Cambridge companion to Newton (pp. 1-32). Cambridge University Press.

Connell, S. M. (2001). Toward an integrated approach to Aristotle as a biological philosopher. The Review of Metaphysics, 55(2), 297-322.

Couzin-Frankel, J. (2019). Beyond survival. Science, 363(6432), 1166-1169.

Cukierman, S. (2006). Et tu, Grotthuss! and other unfinished stories. Biochimica et Biophysica Acta, 1757(8), 876-885.

Davidoff, F., Dixon-Woods, M., Leviton, L., \& Michie, S. (2015). Demystifying theory and its use in improvement. BMJ Quality and Safety, 24(3), 228-238.

Del Soldato, E. (2019). Natural philosophy in the Renaissance. In E. N. Zalta (Ed.), The Stanford Encyclopedia of Philosophy. Metaphysics Research Lab, Stanford University.

Delling, M., Indzhykulian, A. A., Liu, X., Li, Y., Xie, T., Corey, D. P., \& Clapham, D. E. (2016). Primary cilia are not calcium-responsive mechanosensors. Nature, 531(7596), 656-660.

Depew, D. J. (1995). Humans and other political animals in Aristotle's history of animals. Phronesis, 40(2), 156-181.

Deutsch, D. (2015). The logic of experimental tests, particularly of Everettian quantum theory. arXiv, 1508.02048.

Diede, S. J. (2014). Spontaneous regression of metastatic cancer: Learning from neuroblastoma. Nature Reviews Cancer, 14(2), 71-72.

Dilthey, W. (1977). Ideas concerning a descriptive and analytic psychology (1894) Descriptive psychology and historical understanding (R. M. Zaner \& K. L. Heiges, Trans.) (pp. 21-120). Martinus Nijhoff Publishers.

DiMeglio, L. A., Evans-Molina, C., \& Oram, R. A. (2018). Type 1 diabetes. Lancet, 391(10138), 2449-2462.

Dong, J., Panchakshari, R. A., Zhang, T., Zhang, Y., Hu, J., Volpi, S. A., et al. (2015). Orientationspecific joining of AID-initiated DNA breaks promotes antibody class switching. Nature, 525(7567), 134-139. 
Editors. (2016). So long to the silos. Nature Biotechnology, 34, 357.

Ehsani, S. (2012a). Simple variation of the logistic map as a model to invoke questions on cellular protein trafficking. arXiv, 1206.5557.

Ehsani, S. (2012b). Time in the cell: A plausible role for the plasma membrane. arXiv, 1210.0168.

Ehsani, S. (2013a). Correlative-causative structures and the 'pericause': An analysis of causation and a model based on cellular biology. arXiv, 1310.0507.

Ehsani, S. (2013b). Macro-trends in research on the central dogma of molecular biology. arXiv, $1301.2397 \mathrm{v} 2$.

Ehsani, S. (2016). A framework for philosophical biology. arXiv, 1605.00033.

Ehsani, S. (2019). The challenges of purely mechanistic models in biology and the minimum need for a 'mechanism-plus-X' framework. arXiv, 1905.10916.

Einstein, A. (1922). Sidelights on relativity (G. B. Jeffery \& W. Perrett, Trans.). Methuen \& Co.

Elf, J. (2016). Staying clear of the dragons. Cell Systems, 2, 219-220.

Everaert, M. B., Huybregts, M. A., Chomsky, N., Berwick, R. C., \& Bolhuis, J. J. (2015). Structures, not strings: Linguistics as part of the cognitive sciences. Trends in Cognitive Sciences, 19, 729-743.

Feder, M. E., \& Mitchell-Olds, T. (2003). Evolutionary and ecological functional genomics. Nature Reviews Genetics, 4(8), 651-657.

Fisher, J. F., \& Mobashery, S. (2016). Endless resistance. Endless antibiotics? Medicinal Chemistry Communications, 7, 37-49.

Fleming, S. M. (2016). Changing our minds about changes of mind. eLife, 5, e14790.

Frede, M. (1992). Plato's Sophist on false statements. In R. Kraut (Ed.), The Cambridge companion to Plato (pp. 397-424). Cambridge University Press.

Frieboes, H. B., Chaplain, M. A., Thompson, A. M., Bearer, E. L., Lowengrub, J. S., \& Cristini, V. (2011). Physical oncology: A bench-to-bedside quantitative and predictive approach. Cancer Research, 71(2), 298-302.

Friedman, M. (1974). Explanation and scientific understanding. Journal of Philosophy, 71(1), 519.

Galen. (1916). On the natural faculties (A. J. Brock, Trans.). William Heinemann.

Gare, A. (2008). Approaches to the question, 'what is life?': Reconciling theoretical biology with philosophical biology. Cosmos and History: The Journal of Natural and Social Philosophy, 4, 53-77.

Garfinkel, A. (2015). Bad philosophical ideas that are driving modern biology and medicine. MIT Philosophy Colloquium.

Glymour, C., Danks, D., Glymour, B., Eberhardt, F., Ramsey, J., Scheines, R., et al. (2010). Actual causation: A stone soup essay. Synthese, 175(2), 169-192.

Gordon, S. (2016). Phagocytosis: An immunobiologic process. Immunity, 44(3), 463-475.

Gouvêa, D. Y. (2015). Explanation and the evolutionary first law(s). Philosophy of Science, 82(3), 363-382.

Greaves, M. (2018). A causal mechanism for childhood acute lymphoblastic leukaemia. Nature Reviews Cancer, 18(8), 471-484.

Greene, J. (2003). From neural 'is' to moral 'ought': What are the moral implications of neuroscientific moral psychology? Nature Reviews Neuroscience, 4(10), 846-849.

Gregory, R. (2000). Reversing Rorschach. Nature, 404(6773), 19.

Griffiths, P. (2018). Philosophy of biology. In E. N. Zalta (Ed.), The Stanford Encyclopedia of Philosophy. Metaphysics Research Lab, Stanford University.

Gunawardena, J. (2014a). Beware the tail that wags the dog: Informal and formal models in biology. Molecular Biology of the Cell, 25(22), 3441-3444.

Gunawardena, J. (2014b). Time-scale separation - Michaelis and Menten's old idea, still bearing fruit. The FEBS Journal, 281(2), 473-488.

Hatwalne, Y., Ramaswamy, S., Rao, M., \& Simha, R. A. (2004). Rheology of active-particle suspensions. Physical Review Letters, 92(11), 118101.

Hauser, M. D. (2016). Challenges to the what, when, and why. Biolinguistics, 10, 1-5. 
Henry, D. (2018). Aristotle on epigenesis: Two senses of epigenesis. In A. Falcon \& D. Lefebvre (Eds.), Aristotle's generation of animals: A critical guide (pp. 89-107). Cambridge University Press.

Hilfinger, A., Norman, T. M., \& Paulsson, J. (2016). Exploiting natural fluctuations to identify kinetic mechanisms in sparsely characterized systems. Cell Systems, 2, 251-259.

Hoption Cann, S. A., van Netten, J. P., van Netten, C., \& Glover, D. W. (2002). Spontaneous regression: A hidden treasure buried in time. Medical Hypotheses, 58(2), 115-119.

Hosios, A. M., Hecht, V. C., Danai, L. V., Johnson, M. O., Rathmell, J. C., Steinhauser, M. L., et al. (2016). Amino acids rather than glucose account for the majority of cell mass in proliferating mammalian cells. Developmental Cell, 36, 540-549.

Hug, L. A., Baker, B. J., Anantharaman, K., Brown, C. T., Probst, A. J., Castelle, C. J., et al. (2016). A new view of the tree of life. Nature Microbiology, 1, 16048.

Hume, D. (1902). Enquiries concerning the human understanding and concerning the principles of morals. Clarendon Press.

Jaeger, A. M., Stopfer, L., Lee, S., Gaglia, G., Sandel, D., Santagata, S., et al. (2019). Rebalancing protein homeostasis enhances tumor antigen presentation. Clinical Cancer Research, 25(21), 6392-6405.

Jones, O. R., Scheuerlein, A., Salguero-Gomez, R., Camarda, C. G., Schaible, R., Casper, B. B., et al. (2014). Diversity of ageing across the tree of life. Nature, 505(7482), 169-173.

JRA. (2006). Virchow misquoted, part-quoted, and the real McCoy. Journal of Epidemiology and Community Health, 60(8), 671.

Justman, Q. (2016). The power of logic and reason. Cell Systems, 2, 215.

Kadelka, C., Murrugarra, D., \& Laubenbacher, R. (2013). Stabilizing gene regulatory networks through feedforward loops. Chaos, 23(2), 025107.

Kannan, S., \& Tse, D. (2015). Fundamental limits of search. Cell Systems, 1(2), 102-103.

Karmon, A., \& Pilpel, Y. (2016). Biological causal links on physiological and evolutionary time scales. eLife, 5, e14424.

Kolter, R., \& van Wezel, G. P. (2016). Goodbye to brute force in antibiotic discovery? Nature Microbiology, 1, 15020.

Kottke, T. E. (2011). Medicine is a social science in its very bone and marrow. Mayo Clinic Proceedings, 86(10), 930-932.

Kramer, M. (2019). Stats: Is this therapy useful? Nature, 569(7755), 192.

Kryazhimskiy, S., Rice, D. P., Jerison, E. R., \& Desai, M. M. (2014). Microbial evolution. Global epistasis makes adaptation predictable despite sequence-level stochasticity. Science, 344(6191), $1519-1522$.

Laplane, L. (2016). Cancer stem cells: Philosophy and therapies. Harvard University Press.

Lazar, V., Pal Singh, G., Spohn, R., Nagy, I., Horvath, B., Hrtyan, M., et al. (2013). Bacterial evolution of antibiotic hypersensitivity. Molecular Systems Biology, 9, 700.

Ledford, H. (2016). Cocktails for cancer with a measure of immunotherapy. Nature, 532(7598), $162-164$.

Leek, J. T., Scharpf, R. B., Bravo, H. C., Simcha, D., Langmead, B., Johnson, W. E., et al. (2010). Tackling the widespread and critical impact of batch effects in high-throughput data. Nature Reviews Genetics, 11(10), 733-739.

Leigh, F. (2007). Platonic dialogue, maieutic method and critical thinking. Journal of Philosophy of Education, 41(3), 309-323.

Levin, M., Anavy, L., Cole, A. G., Winter, E., Mostov, N., Khair, S., et al. (2016). The middevelopmental transition and the evolution of animal body plans. Nature, 531(7596), 637-641.

Lewis, K. (2012). Antibiotics: Recover the lost art of drug discovery. Nature, 485(7399), 439-440.

Lewontin, R. C. (1998). The evolution of cognition: Questions we will never answer. In D. Scarborough, S. Sternberg, \& D. N. Osherson (Eds.), An invitation to cognitive science: Methods, models, and conceptual issues (Vol. 4, pp. 107-132). MIT Press.

Lewontin, R. C. (2006). Commentary: Statistical analysis or biological analysis as tools for understanding biological causes. International Journal of Epidemiology, 35(3), 536-537. 
Lieshout, P., Ben-David, B., Lipski, M., \& Namasivayam, A. (2014). The impact of threat and cognitive stress on speech motor control in people who stutter. Journal of Fluency Disorders, 40, 93-109.

Lin, A., Giuliano, C. J., Palladino, A., John, K. M., Abramowicz, C., Yuan, M. L., et al. (2019). Off-target toxicity is a common mechanism of action of cancer drugs undergoing clinical trials. Science Translational Medicine, 11(509), eaaw8412.

Ling, S., Hu, Z., Yang, Z., Yang, F., Li, Y., Lin, P., et al. (2015). Extremely high genetic diversity in a single tumor points to prevalence of non-Darwinian cell evolution. Proceedings of the National Academy of Sciences of the United States of America, 112(47), E6496-E6505.

Lister, J. (1957). The medical traveler. The New England Journal of Medicine, 257, 878-879.

Locke, J. (1894). An essay concerning humane understanding, Book II. Clarendon Press.

Lonie, I. M. (1964). Erasistratus, the Erasistrateans, and Aristotle. Bulletin of the History of Medicine, 38, 426-443.

Lopez, H. M., Gachelin, J., Douarche, C., Auradou, H., \& Clement, E. (2015). Turning bacteria suspensions into superfluids. Physical Review Letters, 115(2), 028301.

Losick, R., \& Desplan, C. (2008). Stochasticity and cell fate. Science, 320(5872), 65-68.

Louis, E. J. (2007). Evolutionary genetics: Making the most of redundancy. Nature, 449(7163), 673-674.

MacCoun, R., \& Perlmutter, S. (2015). Blind analysis: Hide results to seek the truth. Nature, 526(7572), 187-189.

Manchak, J., \& Roberts, B. W. (2016). Supertasks. In E. N. Zalta (Ed.), The Stanford Encyclopedia of Philosophy. Stanford, CA: Metaphysics Research Lab, Stanford University.

Marchetti, M. C. (2015). Soft matter: Frictionless fluids from bacterial teamwork. Nature, 525(7567), 37-39.

Markov, I. L. (2014). Limits on fundamental limits to computation. Nature, 512(7513), 147-154.

Martin, R. M. (1980). Primordiality, science, and value. State University of New York Press.

Matta, C. F. (2006). Hydrogen-hydrogen bonding: The non-electrostatic limit of closed-shell interaction between two hydrogen atoms. A critical review. In S. J. Grabowski (Ed.), Hydrogen bonding - new insights: Springer.

McCormick, M. A., Delaney, J. R., Tsuchiya, M., Tsuchiyama, S., Shemorry, A., Sim, S., et al. (2015). A comprehensive analysis of replicative lifespan in 4,698 single-gene deletion strains uncovers conserved mechanisms of aging. Cell Metabolism, 22(5), 895-906.

McNamara, P. (2019). Deontic logic. In E. N. Zalta (Ed.), The Stanford Encyclopedia of Philosophy. Metaphysics Research Lab, Stanford University.

McNeil, J. J., Nelson, M. R., Woods, R. L., Lockery, J. E., Wolfe, R., Reid, C. M., et al. (2018). Effect of aspirin on all-cause mortality in the healthy elderly. The New England Journal of Medicine, 379(16), 1519-1528.

Mill, J. S. (1843). A system of logic, ratiocinative and inductive. John W. Parker.

Moger-Reischer, R. Z., \& Lennon, J. T. (2019). Microbial ageing and longevity. Nature Reviews Microbiology, 17(11), 679-690.

Monaco, A. P., Neve, R. L., Colletti-Feener, C., Bertelson, C. J., Kurnit, D. M., \& Kunkel, L. M. (1986). Isolation of candidate cDNAs for portions of the Duchenne muscular dystrophy gene. Nature, 323(6089), 646-650.

Moya, A. (2015). General systems theory and systems biology. In The calculus of life: Towards a theory of life (pp. 25-30). Springer.

Mozaffari, S. M. (2016). Planetary latitudes in medieval Islamic astronomy: An analysis of the non-Ptolemaic latitude parameter values in the Maragha and Samarqand astronomical traditions. Archive for History of Exact Sciences, 70(5), 513-541.

Nakashige, T. G., Zhang, B., Krebs, C., \& Nolan, E. M. (2015). Human calprotectin is an ironsequestering host-defense protein. Nature Chemical Biology, 11, 765-771.

Nei, M., \& Nozawa, M. (2011). Roles of mutation and selection in speciation: From Hugo de Vries to the modern genomic era. Genome Biology and Evolution, 3, 812-829.

Nesse, R. M. (2013). Tinbergen's four questions, organized: A response to Bateson and Laland. Trends in Ecology and Evolution, 28(12), 681-682. 
Neupane, K., Manuel, A. P., \& Woodside, M. T. (2016). Protein folding trajectories can be described quantitatively by one-dimensional diffusion over measured energy landscapes. Nature Physics, 12, 700-703.

Nicholson, D. J., \& Gawne, R. (2014). Rethinking Woodger's legacy in the philosophy of biology. Journal of the History of Biology, 47(2), 243-292.

Niepel, M., Hafner, M., Mills, C. E., Subramanian, K., Williams, E. H., Chung, M., et al. (2019). A multi-center study on the reproducibility of drug-response assays in mammalian cell lines. Cell Systems, 9(1), 35-48 e5.

Nikiforov, Y. E., Seethala, R. R., Tallini, G., et al. (2016). Nomenclature revision for encapsulated follicular variant of papillary thyroid carcinoma: A paradigm shift to reduce overtreatment of indolent tumors. JAMA Oncology, 2(8), 1023-1029.

Norris, D. P., \& Jackson, P. K. (2016). Cell biology: Calcium contradictions in cilia. Nature, 531(7596), 582-583.

Oates, A. C., Gorfinkiel, N., Gonzalez-Gaitan, M., \& Heisenberg, C. P. (2009). Quantitative approaches in developmental biology. Nature Reviews Genetics, 10(8), 517-530.

Odenbaugh, J. (2013). Searching for patterns, hunting for causes - Robert MacArthur, the mathematical naturalist. In O. Harman \& M. R. Dietrich (Eds.), Outsider scientists: Routes to innovation in biology (pp. 181-198). Chicago: University of Chicago Press.

O’Malley, B. W. (2010). Masters of the genome. Nature Reviews Molecular Cell Biology, 11(5), 311.

Open Science Collaboration. (2015). Estimating the reproducibility of psychological science. Science, 349(6251), aac4716.

Orzack, S. H. (2012). The philosophy of modelling or does the philosophy of biology have any use? Philosophical Transactions of the Royal Society of London. Series B, Biological Sciences, 367(1586), 170-180.

Oster, E. (2015). Unobservable selection and coefficient stability: Theory and evidence. Brown University.

Perrin, J. B. (1926). Discontinuous structure of matter. Nobel Lecture.

Persson, E. K., Verstraete, K., Heyndrickx, I., Gevaert, E., Aegerter, H., Percier, J. M., et al. (2019). Protein crystallization promotes type 2 immunity and is reversible by antibody treatment. Science, 364(6442).

Pigliucci, M. (2013). On the different ways of 'doing theory' in biology. Biological Theory, 7(4), 287-297.

Piskounova, E., Agathocleous, M., Murphy, M. M., Hu, Z., Huddlestun, S. E., Zhao, Z., et al. (2015). Oxidative stress inhibits distant metastasis by human melanoma cells. Nature, 527(7577), 186-191.

Plato. (2015). Theaetetus and Sophist. In C. Rowe (Ed.), Cambridge texts in the history of philosophy (pp. 99-177). Cambridge: Cambridge University Press.

Raspopovic, J., Marcon, L., Russo, L., \& Sharpe, J. (2014). Modeling digits. Digit patterning is controlled by a Bmp-Sox9-Wnt Turing network modulated by morphogen gradients. Science, 345(6196), 566-570.

Rehermann, B. (2016). HCV in 2015: Advances in hepatitis C research and treatment. Nature Reviews Gastroenterology and Hepatology, 13(2), 70-72.

Reker, D., Blum, S. M., Steiger, C., Anger, K. E., Sommer, J. M., Fanikos, J., \& Traverso, G. (2019). "Inactive" ingredients in oral medications. Science Translational Medicine, 11(483), eaau6753.

Robert, A. M. (2011). Nonstandard analysis. Dover Publications.

Robinson, J. P., \& Roederer, M. (2015). Flow cytometry strikes gold. Science, 350(6262), 739-740.

Robustelli, P., Piana, S., \& Shaw, D. E. (2018). Developing a molecular dynamics force field for both folded and disordered protein states. Proceedings of the National Academy of Sciences of the United States of America, 115(21), E4758-E4766.

Rohwer, F., \& Segall, A. M. (2015). In retrospect: A century of phage lessons. Nature, 528(7580), $46-48$.

Romanes, G. J. (1891). Aristotle as a naturalist. Science, 17(422), 128-133. 
Ross-Gillespie, A., Weigert, M., Brown, S. P., \& Kummerli, R. (2014). Gallium-mediated siderophore quenching as an evolutionarily robust antibacterial treatment. Evolution, Medicine, and Public Health, 2014(1), 18-29.

Saade Lemus, P., Anderson, K., Smith, M., \& Bullock, A. (2019). Spontaneous regression of pancreatic cancer with liver metastases. BMJ Case Reports, 12(5), e229619.

Schaapveld, M., Aleman, B. M., van Eggermond, A. M., Janus, C. P., Krol, A. D., van der Maazen, R. W., et al. (2015). Second cancer risk up to 40 years after treatment for Hodgkin's lymphoma. The New England Journal of Medicine, 373(26), 2499-2511.

Scholl, R., \& Nickelsen, K. (2015). Discovery of causal mechanisms: Oxidative phosphorylation and the Calvin-Benson cycle. History and Philosophy of Life Sciences, 37(2), 180-209.

Seeman, J. I., \& Cantrill, S. (2016). Wrong but seminal. Nature Chemistry, 8, 193-200.

Sekikawa, A., Horiuchi, B. Y., Edmundowicz, D., Ueshima, H., Curb, J. D., Sutton-Tyrrell, K., et al. (2003). A "natural experiment" in cardiovascular epidemiology in the early 21 st century. Heart, 89(3), 255-257.

Servick, K. (2019). Humans may sense Earth's magnetic field. Science, 363(6433), 1257-1258.

Shou, W., Bergstrom, C. T., Chakraborty, A. K., \& Skinner, F. K. (2015). Theory, models and biology. eLife, 4, e07158.

Shrinivas, K., Sabari, B. R., Coffey, E. L., Klein, I. A., Boija, A., Zamudio, A. V., et al. (2019). Enhancer features that drive formation of transcriptional condensates. Molecular Cell, 75(3), $549-561$ e7.

Singer, P. N. (2016). Galen. In E. N. Zalta (Ed.), The Stanford Encyclopedia of Philosophy. Stanford, CA: Metaphysics Research Lab, Stanford University.

Smit, S., Rother, K., Heringa, J., \& Knight, R. (2008). From knotted to nested RNA structures: A variety of computational methods for pseudoknot removal. RNA, 14(3), 410-416.

Smith, K. T., Berritt, S., Gonzalez-Moreiras, M., Ahn, S., Smith, M. R., 3rd, Baik, M. H., \& Mindiola, D. J. (2016). Catalytic borylation of methane. Science, 351(6280), 1424-1427.

Spinoza, B. (1992). Ethics: With the Treatise on the emendation of the intellect and Selected letters. (S. Shirley, Trans.). Hackett Publishing Company.

Steffan, J. S. (2016). A cause for childhood ataxia. eLife, 5, e14523.

$\mathrm{Su}$, J. (2018). A brief history of Charcot-Leyden crystal protein/galectin-10 research. Molecules, 23(11), 2931.

Szybalski, W., \& Bryson, V. (1952). Genetic studies on microbial cross resistance to toxic agents. I. Cross resistance of Escherichia coli to fifteen antibiotics. Journal of Bacteriology, 64(4), 489499.

Tadrist, L., \& Darbois-Texier, B. (2016). Are leaves optimally designed for self-support? An investigation on giant monocots. Journal of Theoretical Biology, 396, 125-131.

Tanner, J. M., \& Rutter, J. (2016). You are what you eat... or are you? Developmental Cell, 36, 483-485.

Tauber, A. I. (2003). Metchnikoff and the phagocytosis theory. Nature Reviews Molecular Cell Biology, 4(11), 897-901.

Thamer, M., De Marco, L., Ramasesha, K., Mandal, A., \& Tokmakoff, A. (2015). Ultrafast 2D IR spectroscopy of the excess proton in liquid water. Science, 350(6256), 78-82.

Thompson, A. A., Walters, M. C., Kwiatkowski, J., Rasko, J. E. J., Ribeil, J. A., Hongeng, S., et al. (2018). Gene therapy in patients with transfusion-dependent beta-thalassemia. The New England Journal of Medicine, 378(16), 1479-1493.

Toomer, G. J. (1968). A survey of the Toledan tables. Osiris, 15, 5-174.

Toprak, E., Veres, A., Michel, J. B., Chait, R., Hartl, D. L., \& Kishony, R. (2012). Evolutionary paths to antibiotic resistance under dynamically sustained drug selection. Nature Genetics, 44(1), 101-105.

Tulk, C. A., Molaison, J. J., Makhluf, A. R., Manning, C. E., \& Klug, D. D. (2019). Absence of amorphous forms when ice is compressed at low temperature. Nature, 569(7757), 542-545.

Uphoff, S., Lord, N. D., Okumus, B., Potvin-Trottier, L., Sherratt, D. J., \& Paulsson, J. (2016). Stochastic activation of a DNA damage response causes cell-to-cell mutation rate variation. Science, 351(6277), 1094-1097. 
Van Epps, H. L. (2006). Influenza: Exposing the true killer. The Journal of Experimental Medicine, 203(4), 803.

Varmus, H. (2016). The transformation of oncology. Science, 352(6282), 123.

Vikhanski, L. (2016). Immunity: How Elie Metchnikoff changed the course of modern medicine. Chicago Review Press.

Wallach, D., Kang, T. B., Dillon, C. P., \& Green, D. R. (2016). Programmed necrosis in inflammation: Toward identification of the effector molecules. Science, 352(6281), aaf2154.

Walsh, C. T. (2015). A chemocentric view of the natural product inventory. Nature Chemical Biology, 11(9), 620-624.

Wasserstein, R. L., \& Lazar, N. A. (2016). The ASA's statement on p-values: Context, process, and purpose. The American Statistician, 70(2), 129-133.

Weber, E., Van Bouwel, J., \& De Vreese, L. (2013). How to study scientific explanation? In E. Weber, J. Van Bouwel \& L. De Vreese (Eds.), Scientific explanation (pp. 25-37): Springer.

Wei, X., Prentice, J., \& Balasubramanian, V. (2015). A principle of economy predicts the functional architecture of grid cells. eLife, 4, e08362.

Weiss, J. N., Qu, Z., \& Garfinkel, A. (2003). Understanding biological complexity: Lessons from the past. The FASEB Journal, 17(1), 1-6.

WHO. (2019). Malaria eradication: Benefits, future scenarios and feasibility (Strategic Advisory Group on Malaria Eradication).

Willyard, C. (2016). Cancer therapy: An evolved approach. Nature, 532(7598), 166-168.

Wong, S., \& Slavcev, R. A. (2015). Treating cancer with infection: A review on bacterial cancer therapy. Letters in Applied Microbiology, 61(2), 107-112.

Woodger, J. H. (1929). Biological principles: A critical study. London: Kegan Paul, Trench, Trubner \& Co.

Xie, X. S. (2013). Biochemistry. Enzyme kinetics, past and present. Science, 342(6165), 14571459.

Yang, N., Duong, C. H., Kelleher, P. J., McCoy, A. B., \& Johnson, M. A. (2019). Deconstructing water's diffuse OH stretching vibrational spectrum with cold clusters. Science, 364(6437), 275278.

Yucel, N., Chang, A. C., Day, J. W., Rosenthal, N., \& Blau, H. M. (2018). Humanizing the mdx mouse model of DMD: The long and the short of it. NPJ Regenerative Medicine, 3, 4 .

Zhong, Q., Pevzner, S. J., Hao, T., Wang, Y., Mosca, R., Menche, J., et al. (2016). An inter-species protein-protein interaction network across vast evolutionary distance. Molecular Systems Biology, 12(4), 865.

Zuniga, A., \& Zeller, R. (2014). Development. In Turing's hands - the making of digits. Science, 345(6196), 516-517.

Open Access This chapter is licensed under the terms of the Creative Commons Attribution 4.0 International License (http://creativecommons.org/licenses/by/4.0/), which permits use, sharing, adaptation, distribution and reproduction in any medium or format, as long as you give appropriate credit to the original author(s) and the source, provide a link to the Creative Commons licence and indicate if changes were made.

The images or other third party material in this chapter are included in the chapter's Creative Commons licence, unless indicated otherwise in a credit line to the material. If material is not included in the chapter's Creative Commons licence and your intended use is not permitted by statutory regulation or exceeds the permitted use, you will need to obtain permission directly from the copyright holder.

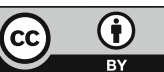

